\title{
Contaminant Boundary at the Faultless Underground Nuclear Test
}

\author{
Prepared by \\ Greg Pohll, Karl Pohlmann, Jeff Daniels, Ahmed Hassan and Jenny Chapman
}

submitted to

Nevada Site Office

National Nuclear Security Administration

U.S. Department of Energy

Las Vegas, Nevada

APRIL 2003

Publication No. 45196 
Reference herein to any specific commercial product, process, or service by trade name, trademark, manufacturer, or otherwise, does not necessarily constitute or imply its endorsement, recommendation, or favoring by the United States Government or any agency thereof or its contractors or subcontractors. The views and opinions of authors expressed herein do not necessarily state or reflect those of the United States Government or any agency thereof.

This report has been reproduced directly from the best available copy.

Available for sale to the public, in paper, from:

U.S. Department of Commerce

National Technical Information Service

5285 Port Royal Rd.

Springfield, VA 22161

phone: 800.553 .6847

fax: 703.605.6000

email: order@ntis.fedworld.gov

online ordering: http://www.ntis.gov/ordering.htm

Available electronically at http://www.doe.gov/bridge

Available for a processing fee to the U.S. Department of Energy and its contractors, in paper, from:

U.S. Department of Energy

Office of Scientific and Technical Information

P.O. Box 62

Oak Ridge, TN 37831-0062

phone: 423.576 .8401

fax: 423.576 .5728

email: reports@adonis.osti.gov 
DOE/NV/13609-24

\title{
Contaminant Boundary at the Faultless Underground Nuclear Test
}

\author{
Prepared by \\ Greg Pohll, Karl Pohlmann, Ahmed Hassan, Jenny Chapman \\ Division of Hydrologic Sciences \\ Desert Research Institute \\ University and Community College System of Nevada \\ and \\ Jeff Daniels \\ Lawrence Livermore National Laboratory \\ Health \& Ecological Assessment Division, Livermore, CA \\ Publication No. 45196 \\ Submitted to \\ Nevada Site Office \\ National Nuclear Security Administration \\ U.S. Department of Energy \\ Las Vegas, Nevada
}

April 2003

The work upon which this report is based was supported by the U.S. Department of Energy under Contract \#DE-AC08-00NV13609. Approved for public release; further dissemination unlimited. 



\section{EXECUTIVE SUMMARY}

The U.S. Department of Energy (DOE) and the Nevada Division of Environmental Protection (NDEP) have reached agreement on a corrective action strategy applicable to address the extent and potential impact of radionuclide contamination of groundwater at underground nuclear test locations. This strategy is described in detail in the Federal Facility Agreement and Consent Order (FFACO, 2000). As part of the corrective action strategy, the nuclear detonations that occurred underground were identified as geographically distinct corrective action units (CAUs). The strategic objective for each CAU is to estimate over a 1,000-yr time period, with uncertainty quantified, the three-dimensional extent of groundwater contamination that would be considered unsafe for domestic and municipal use.

Two types of boundaries (contaminant and compliance) are discussed in the FFACO that will map the three-dimensional extent of radionuclide contamination. The contaminant boundary will identify the region with 95 percent certainty that contaminants do not exist above a threshold value. It will be prepared by the DOE and presented to NDEP. The compliance boundary will be produced as a result of negotiation between the DOE and NDEP, and can be coincident with, or differ from, the contaminant boundary.

Two different thresholds are considered for the contaminant boundary. One is based on the enforceable National Primary Drinking Water Regulations for radionuclides, which were developed as a requirement of the Safe Drinking Water Act. The other is a risk-based threshold considering applicable lifetime excess cancer-risk-based criteria

The contaminant boundary for the Faultless underground nuclear test at the Central Nevada Test Area (CNTA) is calculated using a newly developed groundwater flow and radionuclide transport model that incorporates aspects of both the original three-dimensional model (Pohlmann et al., 1999) and the two-dimensional model developed for the Faultless data decision analysis (DDA) (Pohll and Mihevc, 2000). This new model includes the uncertainty in the threedimensional spatial distribution of lithology and hydraulic conductivity from the 1999 model as well as the uncertainty in the other flow and transport parameters from the 2000 DDA model. Additionally, the new model focuses on a much smaller region than was included in the earlier models, that is, the subsurface within the UC-1 land withdrawal area where the 1999 model predicted radionuclide transport will occur over the next 1,000 years.

The purpose of this unclassified document is to present the modifications to the CNTA groundwater flow and transport model, to present the methodology used to calculate contaminant boundaries, and to present the Safe Drinking Water Act and risk-derived contaminant boundaries for the Faultless underground nuclear test CAU. 



\section{CONTENTS}

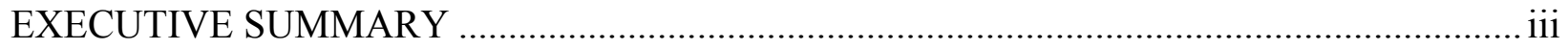

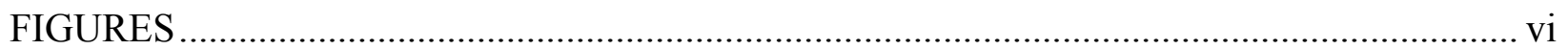

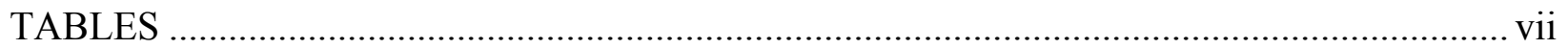

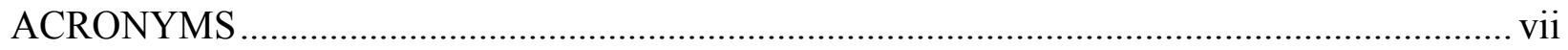

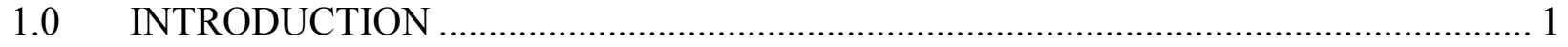

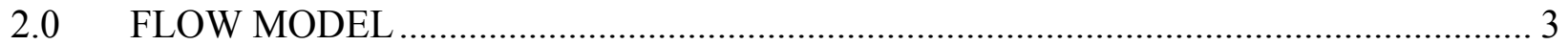

2.1 Conceptualization of Groundwater Flow................................................................ 3

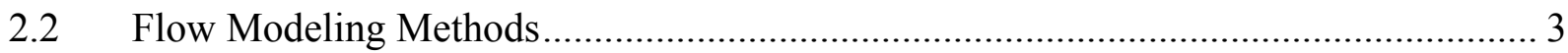

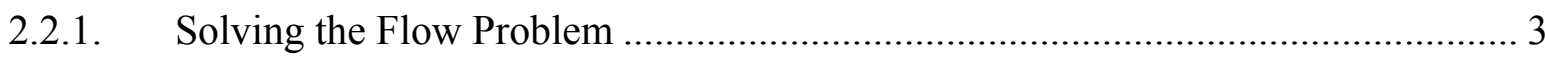

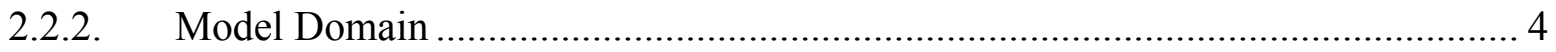

2.2.3. Description of Hydrogeologic Heterogeneity ...................................................... 4

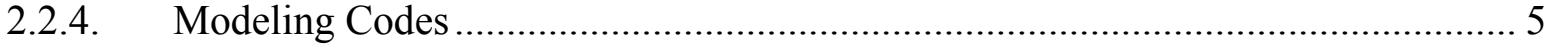

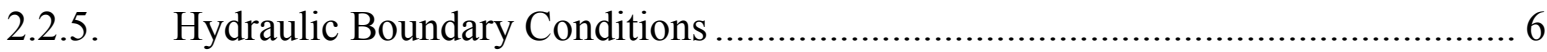

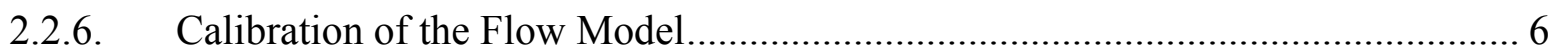

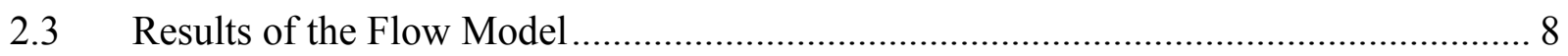

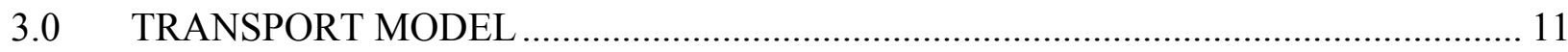

3.1 Conceptualization of Radionuclide Transport ......................................................... 11

3.2 Transport Modeling Methods ............................................................................. 12

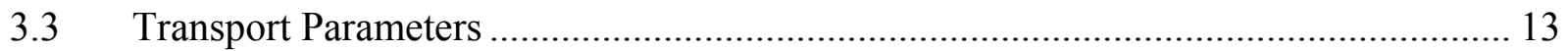

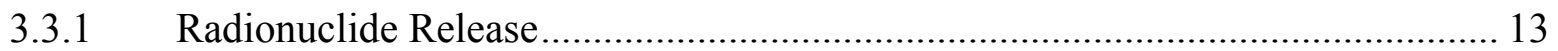

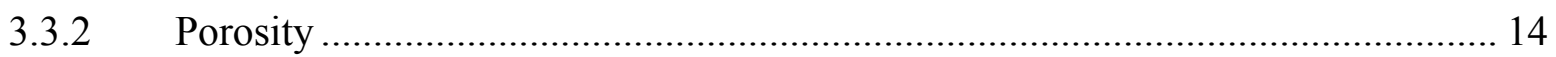

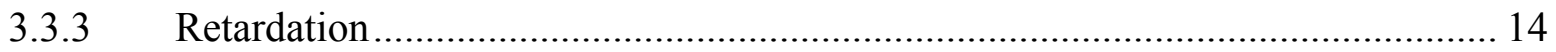

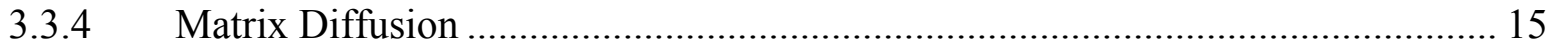

3.4 Transport Model Configuration .............................................................................. 17

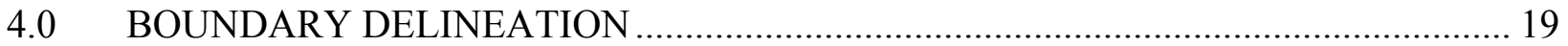

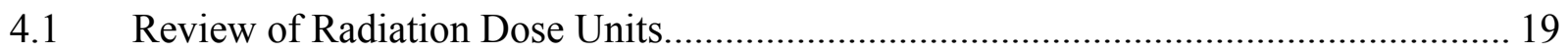

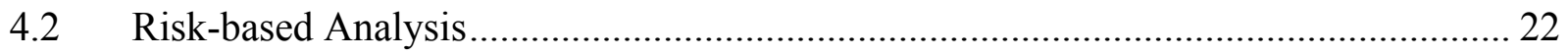

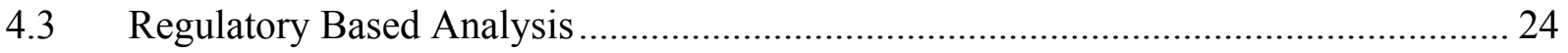

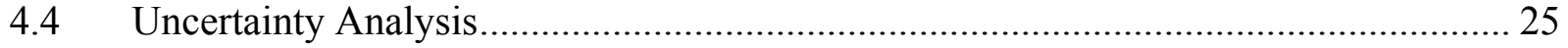

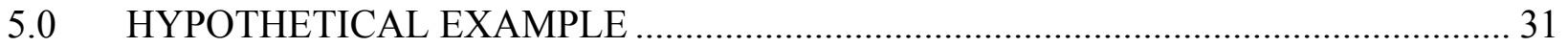

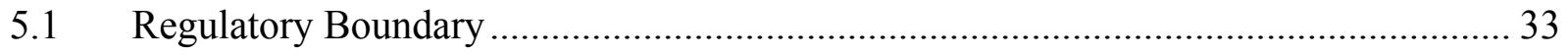




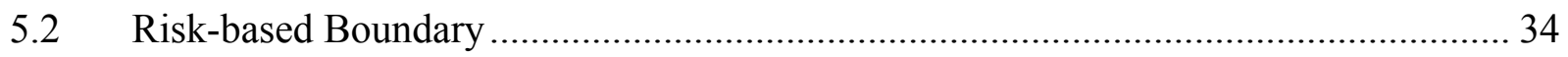

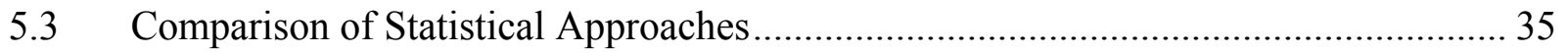

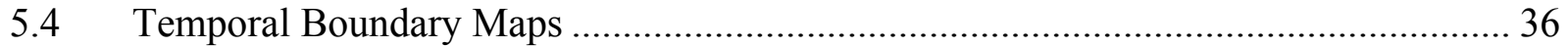

6.0 CONTAMINANT BOUNDARY FOR THE FAULTLESS UNDERGROUND

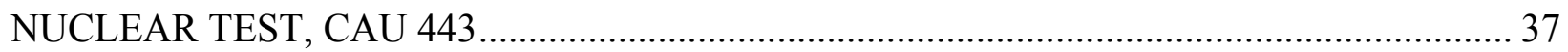

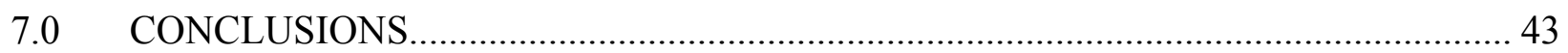

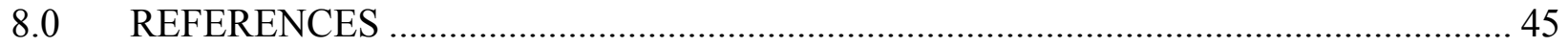

APPENDIX: ASSESSMENT OF THE DEPENDENCE OF SOLUTE TRANSPORT MIGRATION ON DOMESTIC WELL PUMPING …………………………………........... 48

\section{FIGURES}

2.1. Map view of model domain showing the finite difference mesh, the locations of the UC-1 land withdrawal boundary and the related CNTA boreholes.

2.2. Profiles of hydraulic heads simulated by the 1999 model and the new model for well HTH-1, as compared to the measured values. .................................................................. 7

4.1. Probability distribution function showing how typical confidence levels are determined... 27

4.2. Probability distribution function showing how the risk threshold is calculated for the contaminant boundary.

4.3. An example of the probability distribution function and how the risk threshold is calculated for the contaminant boundary.

4.4. An example of a three-dimensional contaminant boundary and the associated mapping to an $\mathrm{x}-\mathrm{y}$ cross section.

5.1. Three-dimensional depiction of the hypothetical groundwater flow and transport model... 31

5.2. Regulatory contaminant boundary at the 95 percent significance level and 1,000 years for uranium, alpha, beta, and all (composite) categories as calculated from the hypothetical model.

5.3. Regulatory (top) and risk-based (bottom) contaminant boundaries at the 95 percent significance level and 1,000 years as calculated from the hypothetical model. 34

5.4. A comparison of the two statistical approaches at 5,50 and 95 percent confidence levels. 35

5.5. A time sequence of the proposed contaminant boundary at the 95 percent significance level as calculated from the hypothetical groundwater flow and transport model. 36

6.1. Contaminant boundary using the risk-based approach at a 95 percent significance level at 100 years after detonation. 38

6.2. Contaminant boundary using the risk-based approach at a 95 percent significance level at 1,000 years after detonation.

6.3. Contaminant boundary using the regulatory based approach at a 95 percent significance level at 100 years after detonation. 
6.4. Contaminant boundary using the regulatory based approach at a 95 percent significance level at 1,000 years after detonation.

A1. Hypothetical groundwater flow and transport components for the two-dimensional flow model.

A2. Spatial distribution of solute concentration for simulations 1 and 2 in the appendix........... 50

A3. Spatial distribution of solute concentration for simulations 3 and 4 in the appendix............ 51

A4. Solute breakthrough curves for simulations 1 and 2 (top) and 3 and 4 (bottom)................. 52

\section{TABLES}

2.1. Uncertainty in selected parameters simulated by the flow model.

3.1. Parameters used to describe the uncertainty in porosity for the three hydrogeologic categories and the welded tuff matrix.

3.2. Parameters used to describe the uncertainty in retardation for reactive solutes in the three hydrogeologic categories.

3.3. Uncertainty ranges for the transfer probabilities used to simulate matrix diffusion in the welded tuff hydrogeologic category.

3.4. Values of parameters that describe the configuration of the transport model and values of deterministic parameters that are assigned the same value for all six transport classes... 17

3.5. Values of parameters specific to individual transport classes. 17

4.1. The morbidity cancer-risk coefficients as derived by EPA (1999) and half-lives for 52 radionuclides.

5.1. Ratio of hydraulic versus glass release, retardation coefficients, and an example isotope as used in the hypothetical solute transport model.

5.2. Radionuclides, transport class, half life, source activity, risk factor, emission type, and MCL as used in the hypothetical transport model.

\section{ACRONYMS}

\begin{tabular}{|c|c|}
\hline $\mathrm{BCF}$ & block-centered flow \\
\hline CAU & Corrective Action Unit \\
\hline CEDE & committed effective dose equivalent \\
\hline $\mathrm{Ci}$ & curie \\
\hline CNTA & Central Nevada Test Area \\
\hline DDA & Data Decision Analysis \\
\hline DOE & U.S. Department of Energy \\
\hline ede & effective dose equivalent \\
\hline EPA & U.S. Environmental Protection Agency \\
\hline FFACO & Federal Facility Agreement and Consent Order \\
\hline GLUE & generalized likelihood uncertainty estimator \\
\hline ICRU & International Commission on Radiation Units and Measurements \\
\hline
\end{tabular}




$\begin{array}{ll}\text { LFG } & \text { lagged Fibonnaci generator } \\ \text { MCL } & \text { maximum containment level } \\ \text { NDEP } & \text { Nevada Division of Environmental Protection } \\ \text { NPDWR } & \text { National Primary Drinking Water Regulations } \\ \text { PCG } & \text { preconditioned-conjugate gradient } \\ \text { pdf } & \text { probability distribution function } \\ \text { RMSE } & \text { root mean square error } \\ \text { RWPT } & \text { random walk particle tracking } \\ \text { SA } & \text { specific activity } \\ \text { SGS } & \text { sequential Gaussian simulation } \\ \text { SI } & \text { International System of Units } \\ \text { SIS } & \text { sequential indicator algorithm } \\ \text { Sv } & \text { units of sievert }\end{array}$




\subsection{INTRODUCTION}

The U.S. Department of Energy (DOE) has a responsibility to assess the potential health risk to workers and the public from possible exposure to environmental contamination resulting from nuclear testing, and the Nevada Division of Environmental Protection (NDEP) is the regulatory agency responsible for protecting public health and the environment in Nevada. These organizations reached agreement on a corrective action strategy applicable to address the extent and potential impact of radionuclide contamination of groundwater at underground nuclear test locations. This strategy is described in detail in Revision 1 to Appendix VI, Section 3, of the Federal Facility Agreement and Consent Order (FFACO, 2000). This corrective action strategy also has undergone an independent technical peer review (ASME/IRS, 2001).

As part of the corrective action strategy, the nuclear detonations that occurred underground were identified as geographically distinct corrective action units (CAUs). The objective for each CAU is to estimate over a 1,000-yr time period, with uncertainty quantified, the threedimensional extent of groundwater contamination that would be considered unsafe for domestic and municipal use. The quantification of the uncertainty is derived from an uncertainty analysis of the flow and transport model. This report identifies various methodologies that could be used to calculate this region of contaminated groundwater.

The contaminant boundaries for the Faultless underground nuclear test at the Central Nevada Test Area (CNTA) are calculated using a newly developed groundwater flow and radionuclide transport model that incorporates aspects of both the original three-dimensional model (Pohlmann et al., 1999) and the two-dimensional model developed for the Faultless data decision analysis (DDA) (Pohll and Mihevc, 2000). The original three-dimensional model was approved by the State of Nevada conditional on additional uncertainty analysis, which was performed in the DDA. To be true to the State's intent for a more rigorous incorporation of uncertainty, DOE/Nevada Operations Office decided to enhance the original three-dimensional model with the uncertainty features developed in the DDA before proceeding with determining contaminant boundaries for Faultless. This new model includes the uncertainty in the threedimensional spatial distribution of lithology and hydraulic conductivity from the 1999 model as well as the uncertainty in the other flow and transport parameters from the 2000 DDA model. Additionally, the new model focuses on a much smaller region than was included in the earlier models; that is, the subsurface within the UC-1 land withdrawal area where the 1999 model predicted radionuclide transport will occur over the next 1,000 years.

Numerical Monte Carlo methods are utilized to incorporate the uncertainty in the stochastic groundwater flow and radionuclide transport model. Calibration of the model is addressed through application of Bayesian methods to weight each realization based on the degree to which the simulated flow field matches the flow field observed at Faultless.

Two types of boundaries are discussed in the FFACO that will map three-dimensional groundwater regions, a contaminant boundary and a compliance boundary. Appendix VI of the FFACO (2000) provides the following description of these boundaries:

"A contaminant boundary is the model-predicted perimeter which defines the extent of radionuclide-contaminated groundwater from underground testing above background conditions exceeding the Safe Drinking Water Act (SDWA) standards. The contaminant boundary will be composed of both a perimeter boundary and a lower hydrostratigraphic unit boundary. The computer model predicts the location of 
this boundary within 1,000 years and must do so at a $95 \%$ level of confidence. Additional results showing contaminant concentrations and the location of the contaminant boundary at selected times will also be presented. These times may include the verification period, the end of the five-year proof of concept period, as well as other times that are of specific interest.

From the contaminant boundary predicted by the computer model, a compliance boundary will be negotiated between NDEP and DOE. The compliance boundary will define the area within which the radiological contaminants above the SDWA standards relative to background are to remain. DOE will be responsible for ensuring compliance with this boundary. The compliance boundary may or may not coincide with the contaminant boundary. If the predicted location of the contaminant boundary cannot be accepted as the compliance boundary, an alternate compliance boundary will be negotiated by both parties."

The water-quality standard used for determining whether groundwater poses a health risk is specified in the FFACO as the National Primary Drinking Water Regulations (NPDWRs) for radionuclides, which were developed as a requirement of the Safe Drinking Water Act. Though not required by the FFACO, consideration should also be given to the criteria that the U.S. Environmental Protection Agency (EPA) considers in establishing regulatory standards for drinking water contaminants. The EPA target range for lifetime excess cancer risk is not to exceed $10^{-4}(1 / 10,000)$ and ideally is less than $10^{-6}(1 / 1,000,000)(\mathrm{EPA}, 2000 \mathrm{a})$, and corresponding maximum contaminant levels (MCLs) for specific radionuclides.

This report is organized to first present the specifics of the revised groundwater flow model and radionuclide transport model. The approach to defining a contaminant boundary is then discussed, beginning with the process of determining what constitutes unsafe water, then proceeding with the process of incorporating uncertainty in the boundary. Examples are shown and discussed. Finally, the contaminant boundary for the Faultless test is presented. 


\subsection{FLOW MODEL}

\subsection{Conceptualization of Groundwater Flow}

There have been no additional data collection efforts at Faultless since the completion of the 1999 model and the conceptualization of groundwater flow has not changed since that time. A brief overview of the conceptual flow model as described by Pohlmann et al. (1999) is included here to reacquaint the reader with the principal components.

The flow model is based on hydrogeologic conditions prior to the Faultless test, under the assumption that transport over the long term is controlled by these factors rather than the relatively short-term effects of the test. Furthermore, flow is considered to be at steady state, owing to the large size of the Hot Creek Valley hydrologic system and the absence of excessive groundwater withdrawals. Local structural features such as faults are not explicitly included due to the lack of information regarding their subsurface locations and hydraulic characteristics.

The principal hydrogeologic units present in the UC-1 land-withdrawal area are divided into three categories, based on their lithologic and hydraulic properties. Category 1 represents Quaternary alluvium containing pebble- to boulder-size fragments enclosed in a clay-cemented matrix. Category 2 consists of Tertiary tuffaceous sediments, bedded tuffs, and partially welded tuffs that exhibit various degrees of alteration (argillation, zeolitization) and thus larger amounts of clay matrix materials than the other two categories. As a result, these rocks have the lowest hydraulic conductivity of the three categories, as demonstrated by the results of the CNTA straddle packer testing (Pohlmann et al., 1999). Tertiary rhyolites and densely welded tuffs comprise Category 3 . These rocks are highly fractured and where spatially connected are considered the primary pathways for groundwater flow and transport at Faultless.

Hydraulic head measurements in wells in Hot Creek Valley indicate that groundwater flow in the alluvium is directed toward the south, generally following the slope of the valley surface. Head relationships in the deeper volcanic system, including surrounding valleys, indicate flow toward the northeast and east toward regional discharge points further south in Hot Creek Valley and east in southern Railroad Valley. Strong vertically downward hydraulic gradients are present north of UC-1, where land surface elevations are higher and recharge from precipitation is likely to be taking place. To the south, strong vertical hydraulic gradients from the volcanic section upward toward the alluvium are present and may be related to the regional discharge. Head measurements at HTH-1 prior to Faultless suggest a very low downward-directed ambient gradient.

\subsection{Flow Modeling Methods}

\subsubsection{Solving the Flow Problem}

The flow modeling closely follows the process established in the 1999 model and though a few enhancements were made to the model in terms of approaches, no new data were incorporated. As was done for the 1999 model, uncertainty and heterogeneity in hydraulic conductivity $(K)$ are incorporated through a Monte Carlo process of generating multiple realizations of three-dimensional maps of $K$ using sequential simulation methods (Deutsch and Journel, 1998). The maps are produced within the original domain, using the same mesh discretization, spatial statistics, and conditioning data as the original model, thus preserving the spatial distribution of the hydrogeologic categories and $K$ at the same scale. The maps are then used to generate distributions of hydraulic head under hydraulic boundary conditions that 
incorporate the uncertainty in head identified in the DDA for these boundaries. This represents an improvement over the 1999 model, which did not incorporate uncertainty in head boundary conditions.

\subsubsection{Model Domain}

The model is reduced in size from the original model because previous modeling demonstrated that areas east, west, and south of the Faultless land withdrawal area (UC-1) do not contribute to predictions of radionuclide migration. The new domain is $3.6 \mathrm{~km}$ long on each side (approximately twice the length of the land withdrawal area) and is centered over UC-1, and like the 1999 model, is aligned in the north-south direction (Figure 2.1). The domain covers the same 1,350-m vertical section included in the 1999 model. Also consistent with the 1999 model, each cell in the uniform mesh is a cube having edge dimensions of $50 \mathrm{~m}$.

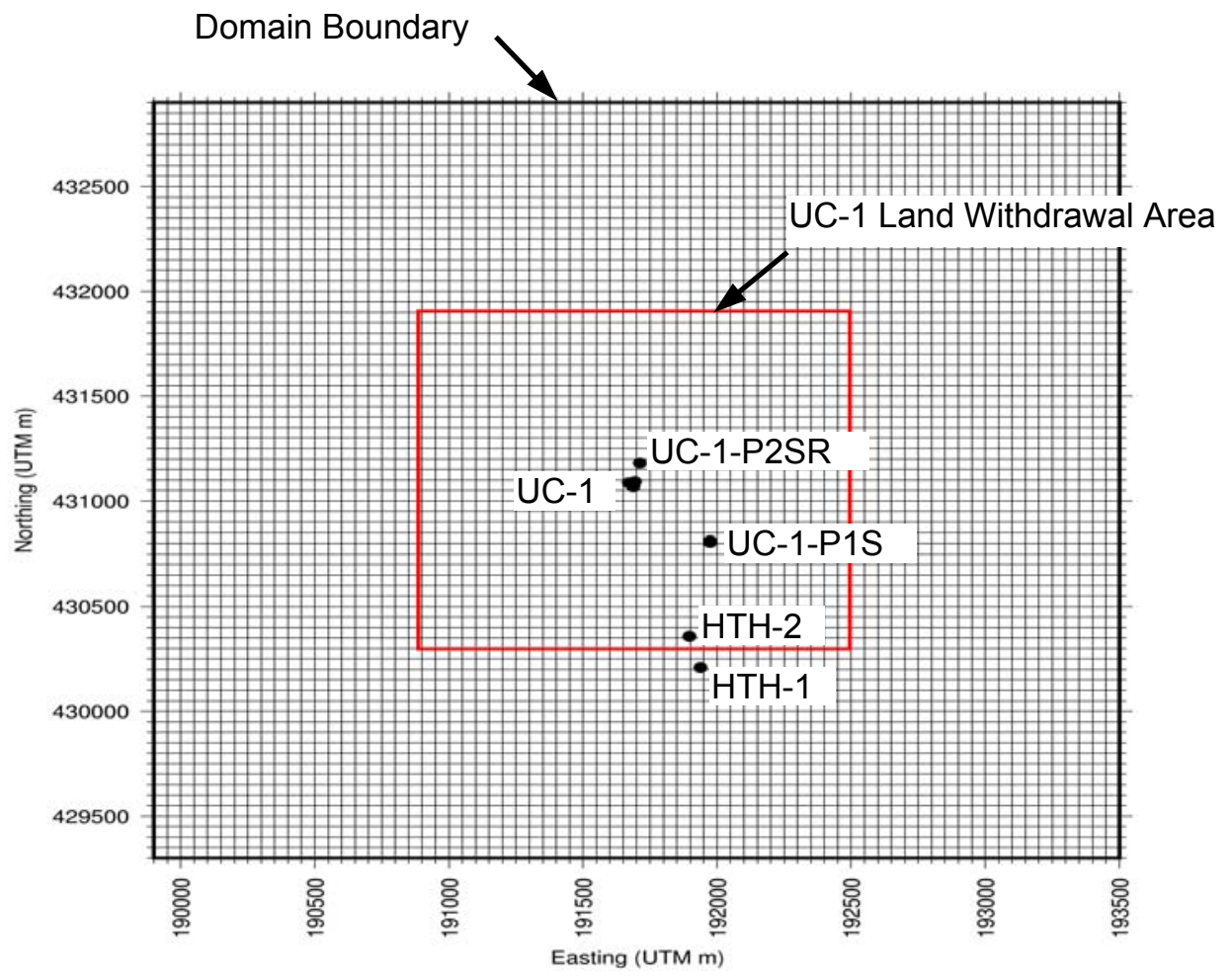

Figure 2.1. Map view of model domain showing the finite difference mesh, the locations of the UC-1 land withdrawal boundary and the related CNTA boreholes.

\subsubsection{Description of Hydrogeologic Heterogeneity}

Maps describing the three-dimensional spatial geometry of the hydrogeologic categories are produced using the sequential indicator simulation (SIS) algorithm (Alabert, 1987). The SIS simulation process, parameter values, and conditioning data are identical to those used in the 1999 model, so the resulting indicator maps match the earlier results. The maps are generated to the full size of the 1999 model domain to incorporate all available indicator conditioning data (i.e., all the wells with lithologic and/or resistivity data) necessary to reproduce the large-scale hydrogeologic structure. The indicator maps are then trimmed to the smaller size of the new domain for use as conditioning for the $K$ maps. 
Five hundred $K$ maps are simulated for the new domain using the sequential Gaussian simulation (SGS) algorithm (Deutsch and Journel, 1998) in the same manner as was used in the 1999 model, though the conditioning data are restricted to wells inside the new, smaller domain. Conditioning data that were utilized in the 1999 model, but lie outside the domain of the new model, do not affect the transport simulations because their distance exceeds the spatial correlation of $K$ and they are not located in the direction of groundwater flow from the Faultless working point. All the parameter values are identical to those in the 1999 model with the exception of the vertical correlation lengths of $K$ for the three hydrogeologic categories. In the 1999 model, correlation lengths of $150 \mathrm{~m}$ were determined from spatial analysis of the CNTA packer tests, but values of $50 \mathrm{~m}$ were used in the base-case flow model to improve calibration. Reconfiguration of the head boundary conditions as uncertain and the utilization of a different calibration procedure in the current model (both described in subsequent sections of this report) allowed a return to the original values of $150 \mathrm{~m}$.

\subsubsection{Modeling Codes}

The SISIM and SGSIM codes (Deutsch and Journel, 1998) are used for the sequential indicator and sequential Gaussian simulations, respectively. The source codes are unmodified, though the original random number generator has been replaced by a lagged Fibonnaci generator (LFG) (Knuth, 1981; Marsaglia, 1985). This generator is initialized for each Monte Carlo realization by setting the seed to the Monte Carlo realization number and is more effective than previously utilized methods for producing streams of independent random deviates. Other codes used in the model that require random number generators have also been adapted to use the LFG.

The modular groundwater flow code MODFLOW-88 (McDonald and Harbough, 1988) is implemented to solve for the hydraulic head field using the finite difference approximation of the general flow equation

$$
\frac{\partial}{\partial x}\left(K_{x x} \frac{\partial h}{\partial x}\right)+\frac{\partial}{\partial y}\left(K_{y y} \frac{\partial h}{\partial y}\right)+\frac{\partial}{\partial z}\left(K_{z z} \frac{\partial h}{\partial z}\right)+W=S_{s} \frac{\partial h}{\partial t}
$$

where $K_{x x}, K_{y y}$, and $K_{z z}$, are values of $K$ along the $x, y$, and $z$ axes, respectively, (m/day), $h$ is the potentiometric head $(\mathrm{m}), W$ is the volumetric flux per unit volume representing sources and/or sinks of water $\left(\mathrm{m}^{-1}\right), S_{s}$ is the specific storage of the porous media $\left(\mathrm{m}^{-1}\right)$, and $t$ is time (day). Equation (2.1) is the most general form of the groundwater flow equation; in the current model, $K$ is heterogeneous (as defined by the $K$ maps), but is isotropic such that $K=K_{x x}=K_{y y}=K_{z z}$. In addition, there are no sources or sinks (i.e., $W=0$ ) and the flow problem is treated as steady state (i.e., $\partial h / \partial t=0)$.

Three modules are used for the application of MODFLOW to Faultless. The Basic (BAS) module specifies the other modules that are to be used, the geometry of the model domain, the boundary conditions, and the time steps. The Block-Centered Flow (BCF) module handles the grid discretization, aquifer type, and hydraulic parameters required to solve the finite difference equations. The Preconditioned Conjugate-Gradient (PCG) module uses modified incomplete Cholesky preconditioning to efficiently solve the matrix of finite difference equations (Hill, 1990). The only modifications made to the original code involved input and output: new routines were added to read the three-dimensional $K$ maps and to save the maps of hydraulic head. 


\subsubsection{Hydraulic Boundary Conditions}

Other than the size of the domain, the groundwater flow model is configured in much the same way as the 1999 model. The northern, southern and bottom faces are specified head boundaries, and the east and west faces are no-flow boundaries (this configuration is based on the predominantly north-south flow patterns simulated in the 1999 model). Heads on the specified-head boundaries are treated as uncertain and are varied using a method adapted from the DDA modeling so that each realization is based on a unique, but equally likely, distribution of boundary heads.

As was done for the 1999 model, boundary heads are estimated using head measurements made in the straddle-packed intervals of the CNTA exploratory wells UCe-20, UCe-18 and HTH-1. For the current model, however, the specified heads include uncertainty through incorporation of the variation observed in the multiple straddle-packed intervals. Just as in the 1999 model, the process uses HTH-1 as the starting point, as it is located much closer to Faultless than the other wells. Estimates of head at the elevations of the top and base of the model at the location of HTH-1 were calculated in the 1999 model by vertical extrapolation of $\mathrm{HTH}-1$ head values. The uncertainty in these values is quantified by the 95 percent confidence interval associated with the linear regression fit to the ten head measurements in HTH-1 (Pohll and Mihevc, 2000). Similarly, the horizontal gradients at the top and base of the model are determined using the uncertainty in the linear regression of head data from UCe-20, UCe-18 and $\mathrm{HTH}-1$. For each Monte Carlo realization, heads at the top and bottom edge nodes of the northern and southern faces are extrapolated using these horizontal gradients and the heads estimated at the top and bottom at the location of HTH-1. The heads of the remaining nodes on the specified head boundaries are obtained by linear interpolation between the heads on the edges.

Using this process, uncertainty in hydraulic head measurements translates into a large degree of variability in the hydraulic boundary conditions of the flow model. Consistent with the conceptual model, groundwater flow is directed downward at the northern end of the domain, upward at the southern end, and to the north along the base.

\subsubsection{Calibration of the Flow Model}

Calibration of the flow model is evaluated using the average of squared differences between the measured head $h_{m}$ and the simulated head $h_{s}$ at each of the ten straddle packer intervals in $\mathrm{HTH}-1$. The root mean square error (RMSE) is calculated for each flow realization $m$ using the expression

$$
\operatorname{RMSE}=\left[1 / n \sum_{i=1}^{n}\left(h_{m}-h_{s}\right)_{i}^{2}\right]_{m}^{0.5}
$$

where $n$ is the number of calibration targets. The RMSE ranges from 0.76 to $8.3 \mathrm{~m}$, with a mean value of $1.7 \mathrm{~m}$, for the full set of 500 Monte Carlo realizations. It should be noted that the calibration of the 1999 model was accomplished through adjustment of the vertical correlation length of $K$ and the mean of $K$ in the alluvium (Category 1) using measured hydraulic heads in the uppermost packer intervals of HTH-1, UCe-18 and UCe-20 as the calibration targets. No adjustments to the construction and parameterization are made in the current model with the exception of the value of the vertical correlation scale of $K$ and the uncertainty incorporated in the head boundary conditions, as described previously. 
Because the construction and parameterization of the current model are both essentially the same as the corresponding volume of the 1999 model, the range of simulated heads, flow directions and fluxes are similar. Comparison of the mean head profiles simulated by both models at the location of HTH-1 shows that the new model provides an improved match to the observed head distribution near UC-1 (Figure 2.2). Calibration of the 1999 model was designed to match heads over a larger region and as a result, simulated heads at HTH-1 were not matched to the degree obtained in the current model. In addition, the closer proximity of the specified head boundaries in the current model results in increased control over heads simulated in the model interior. However, incorporation of uncertainty in the head boundary conditions results in a greater range of simulation results in the current model as compared to the 1999 model, as indicated by the wider range of the 95 percent confidence interval.

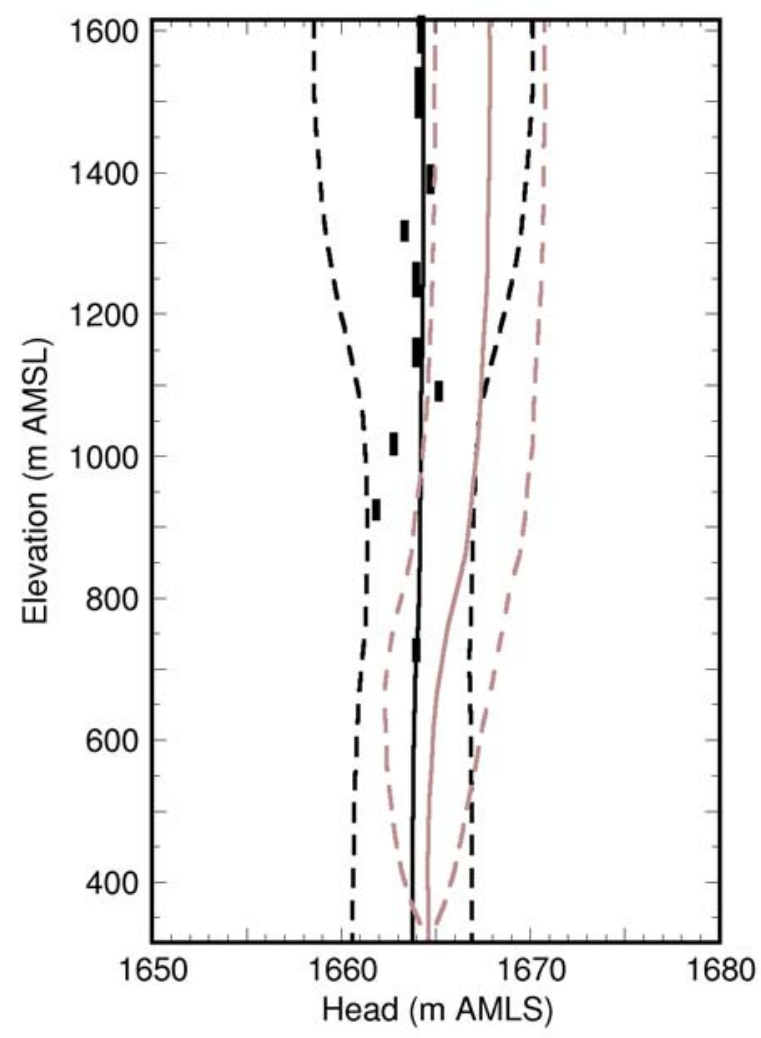

Measured Values
_ Simulated Values, Mean
- Simulated Values, 95\% Confidence Interval
- 1999 Model, Mean
- 1999 Model, 95\% Confidence Interval

Figure 2.2. Profiles of hydraulic heads simulated by the 1999 model and the new model for well HTH-1, as compared to the measured values. 
In a traditional stochastic numerical flow and transport model using Monte Carlo techniques, each of the realizations of flow receives equal weight in the transport analysis. However, it is clear from the range of simulated results that some of the realizations fit the field data better than others. In an effort to honor site-specific field information throughout the modeling process, those realizations that are in good agreement with the field data are given a greater relative weight in the transport modeling than those that are in poor agreement.

The weighting procedure utilized here is the generalized likelihood uncertainty estimator (GLUE) (Beven and Binley, 1992) that extends Monte Carlo random sampling to incorporate the goodness-of-fit of each realization. The goodness-of-fit is quantified by the likelihood measure

$$
L(\vec{Y} \mid \vec{\Theta})=\left[\sum(\varepsilon)^{2}\right]^{-N}
$$

where

$$
\varepsilon=\left(h_{s}-h_{m}\right)_{i}
$$

and $L(\vec{Y} \mid \vec{\Theta})$ is the likelihood of the vector of outputs, $\vec{Y}$ given $\vec{\Theta}$ is the vector of random inputs, $h_{s}$ is the simulated head at the point $i, h_{m}$ is the observed head at that point, and $N$ is a likelihood shape factor. The choice of $N$ is subjective though its value defines its relative function. As $N$ approaches zero, the likelihood approaches unity and each simulation receives equal weight, as in the traditional Monte Carlo analysis. As $N$ approaches infinity, the simulations with the lowest RMSE receive essentially all of the weight, which is analogous to an inverse solution. In this study, the value of $N$ is assumed to be unity, which is a value typically used for this type of analysis (Beven and Binley, 1992; Freer et al., 1996; Morse et al., in review).

Each of the 500 flow realizations are weighted based on an application of the Bayes equation of the form:

$$
P(\vec{\Theta} \mid \vec{Y})=\frac{L(\vec{Y} \mid \vec{\Theta}) P(\vec{\Theta})}{C}
$$

where $P(\vec{\Theta})$ is the prior probability of the input parameters produced by the Monte Carlo simulation, $L(\vec{Y} \mid \vec{\Theta})$ is the likelihood measure from Equation (2.3), $C$ is a normalization constant, and $P(\vec{\Theta} \mid \vec{Y})$ is the posterior density. The posterior density is the probability of the input parameters occurring after taking into account the likelihood measure and is used to calculate the contaminant boundary as described in Section 4.0. Each of the 500 flow realizations receives a weight based on Equation (2.5), which is simply a normalization of the likelihood such that the sum of the weights for all realizations is unity. In this way, each transport realization is appropriately weighted according to the goodness-of-fit of its hydraulic head distribution to the available field measurements.

\subsection{Results of the Flow Model}

Table 2.1 presents summary statistics regarding simulated values of indicator category, $K$, heads at the four specified head edges, values of RMSE for simulated heads, and errors in the mass balance of the flow model. 
Table 2.1. Uncertainty in selected parameters simulated by the flow model.

\begin{tabular}{lcc}
\hline \multicolumn{1}{c}{ Parameter } & Mean & Standard Deviation \\
\hline PDF of Category & & \\
Category 1 & 0.23 & $1.5 \times 10^{-3}$ \\
Category 2 & 0.48 & $6.4 \times 10^{-2}$ \\
Category 3 & 0.29 & $6.4 \times 10^{-2}$ \\
Hydraulic Conductivity, $\log _{10}[K(\mathrm{~m} / \mathrm{d})]$ & & \\
Category 1 & -0.72 & 0.03 \\
Category 2 & -2.6 & 0.006 \\
Category 3 & -0.46 & 0.008 \\
Hydraulic Head on Boundaries, $h_{s}(\mathrm{~m}$ AMSL) & & 5.9 \\
North, Top & 1670.6 & 6.4 \\
North, Base & 1652.4 & 2.3 \\
South, Top & 1662.3 & 2.7 \\
South, Base & 1668.6 & 0.74 \\
RMSE (m) & 1.70 & 0.009 \\
Mass Balance Error (In-Out, \%) & -0.001 & \\
\hline
\end{tabular}





\subsection{TRANSPORT MODEL}

\subsection{Conceptualization of Radionuclide Transport}

Although no additional field work has been conducted at Faultless since the completion of the 1999 model, significant improvements have been made to the radionuclide transport code for simulating matrix diffusion processes and refined values of retardation parameters have been obtained through continued laboratory experiments. Furthermore, following the lead of the Faultless DDA model, many of the transport parameters that were treated as deterministic in the 1999 model are now treated as uncertain. These parameters include effective porosity for each of the three hydrogeologic categories, porosity of the welded tuff matrix, matrix diffusion parameters, and dissolution from the nuclear melt glass. Additionally, sorption and geochemical release parameters are treated as uncertain for transport cases that include sorbing radionuclides.

With the exceptions noted above, the general conceptualization of radionuclide transport at Faultless simulated in the 1999 model is maintained. A brief overview of the principal components of the conceptual transport model is included here; the reader is referred to Pohlmann et al. (1999) for complete descriptions. Aspects of the model that differ from the earlier model and the methods developed to incorporate them are presented in the Section 3.2.

The contaminants of interest are the radionuclides produced by the Faultless test and the daughter products created through radioactive decay. All of the initial radionuclide mass is assumed to be located within the cavity; no prompt injection into the surrounding formations is included. The mass data for the radionuclides produced by Faultless remain classified and cannot be presented in a public document. Transport calculations are performed here using a unit value as the initial mass. The transport results based on unit values of initial mass are then converted to true mass in a classified companion document. To make the general results of the 1999 transport model publicly available, Pohlmann et al. (1999) estimated the initial mass of ${ }^{3} \mathrm{H}$ using the highest concentration measured in water samples from post-test well UC-1-P-2SR and a generic relationship related to depth of burial (Glasstone and Dolan, 1977). The initial mass for ${ }^{3} \mathrm{H}$ estimated in this way and used for the construction of the boundary maps in the current model is $2.6 \times 10^{18} \mathrm{pCi}$.

Radionuclides are apportioned according to their volatility among surface deposits and volume deposits in nuclear melt glass. Nuclides within the glass are released to the groundwater according to their glass dissolution behavior and melt glass characteristics while those forming surface deposits are immediately available for transport by groundwater. However, it is assumed that no migration occurs until the cavity and chimney have refilled with groundwater and hydraulic equilibrium conditions have been reestablished, which is estimated to occur 30 years after the nuclear test. Molecular diffusion is neglected during this infill period, presuming that the flow of groundwater toward the hydraulic sink is much larger than the migration of radionuclides away from the sink driven by concentration gradients (Pohlmann et al., 1999, Appendix 3).

The radionuclides produced by the nuclear test are grouped into six transport classes based on their ratio of hydraulic release to geochemical release (glass dissolution) and their retardation factor as they are transported by advection through the hydrogeologic environment. Diffusion of radionuclides from fractures into surrounding matrix blocks in hydrogeologic Category 3 is also considered. Parameters for simulating retardation and diffusion processes are estimated from laboratory experiments using cores from CNTA exploratory boreholes. Nuclides are grouped 
according to assumed general sorptive behavior and assigned the same retardation values because comprehensive radionuclide-specific data are not available for the Faultless environment.

\subsection{Transport Modeling Methods}

The random walk particle tracking (RWPT) method is used to simulate the transport and fate of radionuclides within the random velocity fields generated by the flow model. The RWPT code used in the 1999 model has been substantially updated to improve the handling of the spatial variability of dispersion and porosity, to incorporate a new approach for simulating the matrix diffusion process, and to include a number of other enhancements.

Traditional random walk methods (e.g., Kinzelbach, 1988; Tompson and Gelhar, 1990) usually rely on the assumption that medium properties such as porosity, $\theta$, and dispersion coefficient, $D$, are sufficiently smooth in space. Discontinuities in effective subsurface transport properties that may arise in discrete velocity fields of numerical groundwater flow models violate this smoothness assumption (LaBolle et al., 2000). Therefore, when $\theta$ or $D$ is discontinuous, these standard methods fail (LaBolle et al., 1996) because the gradient terms of $D$ and/or $\theta$ cannot be formally defined. LaBolle et al. (2000) developed generalized stochastic differential equations applicable to the case of discontinuous coefficients (e.g., dispersion coefficients) and developed a new random walk method that numerically integrates these equations. That method is applicable for cases of abrupt changes in transport parameters and velocity values. The new random-walk equations proposed by LaBolle et al. (2000) can be written as

$$
\boldsymbol{X}_{t+\Delta t}=\boldsymbol{X}_{t}+\left[\boldsymbol{V}\left(\boldsymbol{X}_{t}, t\right)\right] \Delta t+\left[2 \mathbf{D}\left(\boldsymbol{V}\left(\boldsymbol{X}_{t}+\delta \boldsymbol{X}\right), t\right) \Delta t\right]^{1 / 2} \cdot \boldsymbol{Z}
$$

where the displacement vector $\delta \boldsymbol{X}$ is defined as

$$
\delta \boldsymbol{X}=\left[2 \mathbf{D}\left(\boldsymbol{V}\left(\boldsymbol{X}_{t}, t\right)\right) \Delta t\right]^{1 / 2} \cdot \boldsymbol{Z}
$$

The approach evaluates the advective component of particle movement using the velocity at the current particle position, $\left(x_{t}, y_{t}, z_{t}\right)$, and at time $t$. The dispersive component is performed using dispersive coefficients evaluated at an intermediate location, $\left(x_{t}+\delta x, y_{t}+\delta y, z_{t}+\delta z\right)$, where the increments $\delta x, \delta y$, and $\delta z$ represent dispersive steps from the current location, $\left(x_{t}, y_{t}, z_{t}\right)$ to the intermediate location $\left(x_{t}+\delta x, y_{t}+\delta y, z_{t}+\delta z\right)$. The details of the approach and how it is incorporated in the RWPT code are described in Pohlmann et al. (2002).

The transport approach described thus far is appropriate for a porous medium; however, the conceptualization of the flow system at Faultless includes highly fractured zones (Category 3, which has correspondingly high flow velocities) adjacent to unfractured porous zones (Categories 1 and 2). A continuum approach is applied in the sense that effective fracture properties (high $K$ and low porosity) are randomly assigned to the model cells rather than direct incorporation of discrete fractures. As a result, particles are tracked through space in the same manner as for a porous medium, but they experience high flow velocities when they pass through a fracture cell.

Matrix diffusion is incorporated using the physically based method presented by Liu et al. (2000) that uses particle transfer probabilities to describe the diffusion of particles into the matrix and back into the fractures. This method assumes that each grid cell contains two overlapping 
continua: one represents the fractures containing the rapid migration of groundwater and solutes, the second represents the surrounding matrix blocks that have a larger quantity of water (owing to the higher porosity of the matrix), but where advection is negligible. The expression for the forward transition probability is given by Liu et al. (2000) as

$$
P_{f m}=\frac{2 D_{f m}^{*} A}{V_{f}(1-\lambda)(B-b)} \Delta t
$$

where $P_{f m}$ is the probability that a particle in a fracture will diffuse into the matrix, $D_{f m}^{*}$ is the hydrodynamic dispersion coefficient between fractures and matrix, $A$ is the fracture surface area, $V_{f}$ is the volume of water in the fractures, $\lambda$ is a shape factor expressing how the matrix volume increases as one approaches the center of the matrix block (e.g., $\lambda=1 / 3$ for parallel fractures), $B$ is the half spacing between the fractures, $b$ is the fracture half-aperture, and $\Delta t$ is the time step. Particles in fractures diffuse into the matrix according to $P_{f m}$ where they are subjected to local advection within the matrix (if any; none is assumed here for Faultless), and dispersion/diffusion.

Particles can also diffuse back from the matrix to the fractures according to the reverse transfer probability, $P_{m f}$, where they are then moved at the local groundwater velocity within the fracture. This approach provides a finite limit on the size of matrix blocks, and thus limited, rather than infinite, diffusion capacity of the blocks. However, as presented by Liu et al. (2000), the transfer probabilities account only for nonreactive solute transport. To describe matrix diffusion of sorbing radionuclides, we have modified the method to incorporate equilibrium adsorption characterized by a linear isotherm, which transforms the reverse transfer probability according to the appropriate retardation factor. Pohlmann et al. (2002) describe the modified approach and present the expression for the reverse transfer probability, which conservatively ignores sorption in the fractures, as

$$
P_{m f}=\frac{2 D_{m f}^{*} A}{V_{m}(1-\lambda)(B-b)} \Delta t
$$

where $P_{m f}$ is the probability that a particle in the matrix will diffuse back into a fracture, and $V_{m}$ is the volume of water in the matrix block. The selection of the appropriate transfer probabilities for the Faultless case is presented below in Section 3.3.4.

\subsection{Transport Parameters}

\subsubsection{Radionuclide Release}

The rock, fission products, and components of the nuclear device that are vaporized by the tremendous heat and pressure of the nuclear explosion quickly begin to condense and coalesce into a melt glass that contains a significant portion of the radioactivity produced by the nuclear reaction. The slow dissolution of this glass by groundwater releases radionuclides to the flow system where they can be transported away from the cavity and chimney. The release process is described by the geochemical release rate, which is a function of the linear rate constant for mass transfer between the solid and liquid phases, the specific surface area of the glass matrix, and the gram formula weight of the glass matrix (Pohlmann et al., 1999). Uncertainty in the release rate is developed from a uniform $\log _{10}$ distribution of specific surface area, with endpoints of 10 and $100 \mathrm{~cm}^{2} / \mathrm{gm}$ (Bourcier et al., 2000), as was done in the DDA. 


\subsubsection{Porosity}

The ranges in effective porosity uncertainty for the three hydrogeologic categories are the same as those used in the DDA. The lognormal distributions of effective porosity for the alluvium and tuffaceous sediments categories are derived from measurements of total porosity of CNTA cores, a reasonable approximation considering that these sediments are primarily nonindurated and nonwelded and thus incorporate flow and transport only within the matrix. On the other hand, flow and transport in the welded tuffs and rhyolites is assumed to occur primarily in fractures and faults and thus measurements of fracture porosity are required. The uncertainty in fracture porosity of Category 3 was obtained from the literature because the CNTA database does not include these data. This distribution is uniform $\log _{10}$ and ranges between 0.001 and 0.01 .

In addition to the fracture porosity, the matrix porosity of the welded tuff is required to calculate two other transport parameters: the retardation in the matrix and the transfer probability for diffusion from the matrix to the fractures. The range in porosity of the Category 3 matrix is treated as a lognormal distribution based on the measurements of total porosity reported in the CNTA database for cores of welded tuff. Table 3.1 lists the statistical parameters used to describe the four porosity distributions.

Table 3.1. Parameters used to describe the uncertainty in porosity for the three hydrogeologic categories and the welded tuff matrix.

\begin{tabular}{lllc}
\hline \multicolumn{1}{c}{ Category } & Distribution Type & Mean & Standard Deviation \\
\hline Alluvium $\theta_{e}$ & Lognormal & 2.92 & 0.30 \\
Tuffaceous Sediments $\theta_{e}$ & Lognormal & 2.78 & 0.42 \\
Welded Tuff $\theta_{e}$ & Uniform $\log _{10}$ & -3.0 (minimum) & -2.0 (maximum) \\
Welded Tuff $\theta_{m}$ & Lognormal & 2.68 & 0.39 \\
\hline
\end{tabular}

\subsubsection{Retardation}

Retardation of radionuclides through the chemical sorption process is approximated using a linear isotherm that is parameterized by a retardation coefficient in the transport model. This is the same bulk sorption approach that was applied in the 1999 and DDA models. The retardation coefficients are determined for representative reactive solutes from laboratory batch experiments conducted at DRI using rock samples from each of the three hydrogeologic categories. The expression for the retardation coefficient is

$$
R=1+\frac{\rho_{b} K_{d}}{\theta}
$$

where $\rho_{b}$ is the bulk density of the sample, $K_{d}$ is the distribution coefficient determined as the ratio of the mass of sorbate sorbed per mass of sorbent to the aqueous concentration of sorbate, and $\theta$ is the porosity. The values of bulk density are $2.04,2.01$, and $2.20 \mathrm{gm} / \mathrm{cm}^{3}$ for the alluvium, tuffaceous sediments, and welded tuff, respectively (Pohlmann et al., 1999).

The $K_{d}$ values are taken as the slope of the linear regression of equilibrium concentration versus sorbed concentration for each solute at a $\mathrm{pH}$ of 8 . These field-scale values of $K_{d}$ are then adjusted to the scale of the model by considering the specific surface area of the adsorbent used in the experiments to that of the bulk aquifer materials as collected from the cores (as described 
in Pohlmann et al., 1999). Uncertainty in $K_{d}$ is quantified through standard linear regression error analysis, which leads to a t-distribution for $K_{d}$. The other random term in the retardation expression, porosity, is also varied through the uncertainty range appropriate for each hydrogeologic category to produce the final distributions of the retardation coefficient. Table 3.2 lists the parameters used to define the retardation uncertainty in the alluvium, tuffaceous sediments and welded tuff matrix for the six classes of radionuclide transport.

Table 3.2. Parameters used to describe the uncertainty in retardation for reactive solutes in the three hydrogeologic categories. The uncertainty ranges for effective porosity are listed in Table 3.3.

\begin{tabular}{lclc}
\hline \multicolumn{1}{c}{ Category } & Distribution Type & Mean & Standard Deviation \\
\hline Transport Class 3 & & & \\
$\quad$ Alluvium $K_{d}$ & $\mathrm{t}_{1}$ & $1.32 \times 10^{-2}$ & $1.30 \times 10^{-3}$ \\
$\quad$ Tuffaceous Sediments $K_{d}$ & $\mathrm{t}_{1}$ & $1.16 \times 10^{-3}$ & $1.14 \times 10^{-4}$ \\
$\quad$ Welded Tuff Matrix $K_{d}$ & $\mathrm{t}_{1}$ & $6.11 \times 10^{-4}$ & $2.22 \times 10^{-5}$ \\
Transport Class 4 & & & \\
$\quad$ Alluvium $K_{d}$ & $\mathrm{t}_{1}$ & $4.87 \times 10^{-5}$ & $1.89 \times 10^{-5}$ \\
$\quad$ Tuffaceous Sediments $K_{d}$ & $\mathrm{t}_{1}$ & $1.98 \times 10^{-5}$ & $1.89 \times 10^{-5}$ \\
$\quad$ Welded Tuff Matrix $K_{d}$ & $\mathrm{t}_{1}$ & $2.47 \times 10^{-5}$ & $1.89 \times 10^{-5}$ \\
Transport Class 5 & & & \\
$\quad$ Alluvium $K_{d}$ & $\mathrm{t}_{1}$ & $3.27 \times 10^{-4}$ & $6.16 \times 10^{-5}$ \\
$\quad$ Tuffaceous Sediments $K_{d}$ & $\mathrm{t}_{1}$ & $7.10 \times 10^{-4}$ & $6.49 \times 10^{-5}$ \\
$\quad$ Welded Tuff Matrix $K_{d}$ & $\mathrm{t}_{1}$ & $3.13 \times 10^{-4}$ & $5.33 \times 10^{-5}$ \\
Transport Class 6 & & & \\
$\quad$ Alluvium $K_{d}$ & $\mathrm{t}_{1}$ & $6.20 \times 10^{-3}$ & $7.74 \times 10^{-4}$ \\
$\quad$ Tuffaceous Sediments $K_{d}$ & $\mathrm{t}_{1}$ & $3.03 \times 10^{-3}$ & $1.98 \times 10^{-4}$ \\
$\quad$ Welded Tuff Matrix $K_{d}$ & $\mathrm{t}_{1}$ & $3.06 \times 10^{-3}$ & $1.51 \times 10^{-4}$ \\
\hline
\end{tabular}

\subsubsection{Matrix Diffusion}

As described in Section 3.2.1, particle transfer probabilities account for diffusion between the fractures and the rock matrix in the RWPT code. Unfortunately, the parameters required to compute the transfer probabilities expressed in Equations (3.3) and (3.4) are very difficult to estimate, and no field tracer test data are available at CNTA for calibration. In the absence of this information, we have estimated the transfer probabilities from the matrix diffusion parameter $\kappa$ using an empirical relationship between $P_{f m}$ and $\kappa$ developed through numerical modeling studies by Hassan and Mohammed (2003). According to their work, the two parameters can be related through the expression

$$
P_{f m}=0.26 \kappa \Delta t
$$

where $\kappa\left(\right.$ days $\left.^{-1 / 2}\right)$ is the matrix diffusion parameter and $\Delta t$ is the time step used in the transport model. The matrix diffusion parameter is defined (Cvetkovic and Dagan, 1994) as

$$
\kappa=\theta_{m} \frac{\sqrt{D_{m}^{*} R_{m}}}{b}
$$

where $\theta_{m}$ is the matrix porosity, $D_{m}^{*}$ is the effective diffusion coefficient in the rock matrix ( $\mathrm{m}^{2} /$ day), $R_{m}$ is the dimensionless retardation coefficient in the rock matrix, and $b$ is the effective half aperture of the fractures $(\mathrm{m})$. 
Uncertainty in $\kappa$ was incorporated in the DDA through Monte Carlo sampling of Equation (3.7) with all of the included parameters assumed to be random. However, when the DDA values of $\kappa$ are substituted in Equation (3.6), the time steps must be on the order of $10^{-3}$ days or less to obtain values of $P_{f m}$ that do not exceed the maximum allowable transfer probability of one. Considering that the total time for which the contaminant boundary maps are calculated is 1,000 years, time steps of this length would result in RWPT simulations having prohibitively long computational times.

An alternate and in fact more conservative approach used here is to generate the distribution for $\kappa$ using the mean value from the 1999 model and assign the appropriate range of uncertainty from the DDA model, followed by the generation of the random distribution in the forward transfer probability using Equation (3.6). Using field and laboratory data from Faultless where available and augmented by information from the literature, Pohlmann et al. (1999) estimated the deterministic value of $\kappa$ to be 0.03 for the nonsorbing radionuclide ${ }^{3} \mathrm{H}$. This value is used as the mean to generate a $\log _{10}$ distribution of $\kappa$, maintaining the relative variation about the mean defined by the standard deviation of the DDA $\kappa$ distribution by maintaining the coefficient of variation, $c v$, between distributions. The coefficient of variation is defined as $c v=s / \bar{x}$, where $s$ is the standard deviation and $\bar{x}$ is the mean of the distribution. The target values of the mean and standard deviation for the arithmetic $\kappa$ distribution are 0.03 and 0.04 , respectively, and the corresponding mean and standard deviation of the $\log _{10}$ distribution are adjusted to obtain these target values.

The reverse transfer probabilities are obtained through combination of Equations (3.3) and (3.4) as

$$
\frac{P_{f m}}{P_{m f}}=\frac{V_{m}}{V_{f}}=\frac{\theta_{m} V_{t}}{\theta_{f} V_{t}}
$$

where $\theta_{m}$ is the matrix porosity of the welded tuff, $\theta_{f}$ is the fracture porosity, and $V_{t}$ is the total volume of the matrix-fracture system. Equation (3.8) is solved for $P_{f m}$ to obtain

$$
P_{m f}=P_{f m} \frac{\theta_{f}}{\theta_{m}}
$$

The parameters describing the uncertainty in the matrix diffusion parameters are listed in Table 3.3 .

Table 3.3. Uncertainty ranges for the transfer probabilities used to simulate matrix diffusion in the welded tuff hydrogeologic category.

\begin{tabular}{cccc}
\hline Parameter & Distribution Type & Mean & Standard Deviation \\
\hline Forward Probability, $P_{f m}$ & Lognormal & 0.23 & 0.25 \\
Reverse Probability, $P_{f m}$ & Lognormal & 0.009 & 0.016 \\
\hline
\end{tabular}

Matrix diffusion is incorporated only in the fractured densely welded tuffs and rhyolites of Category 3; the other categories are considered unfractured, so matrix diffusion is not included. The spatial variability of matrix diffusion properties is not considered. When first released, the radionuclide source is assumed to exist only in the fractures. 


\subsection{Transport Model Configuration}

The Faultless transport calculations employ the random walk particle tracking method and the three-dimensional Darcy flux fields using the same grid discretization and domain size as the groundwater flow model. The radionuclide source is assumed to be the entire Faultless cavity, which is simulated in the model as a cube having edge lengths of $200 \mathrm{~m}$, and within which particles are uniformly distributed. The values of the transport parameters that are not treated as uncertain are listed in Table 3.4. The time-step length for each realization is calculated within the RWPT code using the values of porosity for the three categories associated with that realization. Time-step lengths are chosen so that the Courant numbers for the realization are less than one to ensure that particles are not transported a distance equal to the dimension of one grid cell $(50 \mathrm{~m})$ in a single time step.

Table 3.4. Values of parameters that describe the configuration of the transport model and values of deterministic parameters that are assigned the same value for all six transport classes. Time step length is variable because it is determined for each realization from the maximum velocity.

\begin{tabular}{lc}
\hline \multicolumn{1}{c}{ Parameter } & Value \\
\hline Location of Source, Nevada Central Coordinates & \\
Easting (m) & 191,675 \\
Northing (m) & 431,075 \\
Elevation (m AMSL) & 885 \\
Edge Length of Source (m) & 200 \\
Source Mass, $M_{0}$ & 1.0 \\
Infill Time (years) & 30 \\
Total Simulation Time (years) & 1,000 \\
Time Step Length, $\Delta t$ (days) & 2.5 to $1,526.8$ \\
Longitudinal Dispersivity & 0.05 \\
Transverse Dispersivity & 0.005 \\
Molecular Diffusion & 0.0 \\
Number of Realizations & 500 \\
\hline
\end{tabular}

The radionuclides chosen for inclusion in the model are grouped into six solute classes based on their ratio of hydraulic release to geochemical release, geochemical release coefficient, and retardation factor (Table 3.5). The transport of the radionuclides in each solute class is simulated as a group. Radioactive decay was not incorporated in the transport model, but was applied in post-processing for each individual nuclide. Each transport class is simulated with a unit source mass and then individual radionuclide responses are calculated in a classified environment where the true source mass is included in the analysis. The decay process, including in-growth, is included at this point for individual radionuclides.

Table 3.5. Values of parameters specific to individual transport classes.

\begin{tabular}{|c|c|c|c|c|c|c|}
\hline Parameter & Class 1 & Class 2 & Class 3 & Class 4 & Class 5 & Class 6 \\
\hline \\
\hline \multicolumn{7}{|l|}{$\begin{array}{l}\text { Release Ratio } \\
\text { Hydraulic Release/ }\end{array}$} \\
\hline Geochemical Release & $1.0 / 0.0$ & $0.5 / 0.5$ & $0.6 / 0.4$ & $0.05 / 0.95$ & $0.8 / 0.2$ & $0.05 / 0.95$ \\
\hline Number of Particles & 20,000 & 20,000 & 20,000 & 40,000 & 20,000 & 40,000 \\
\hline Radionuclides & $\begin{array}{c}{ }^{3} \mathrm{H},{ }^{14} \mathrm{C}, \\
{ }^{85} \mathrm{Kr},{ }^{85} \mathrm{Rb}\end{array}$ & ${ }^{36} \mathrm{Cl},{ }^{129} \mathrm{I}$ & ${ }^{90} \mathrm{Sr},{ }^{90} \mathrm{Y}$, & ${ }^{99} \mathrm{Tc}$ & ${ }^{137} \mathrm{Cs}$ & $\begin{array}{c}{ }^{151} \mathrm{Sm},{ }^{152} \mathrm{Eu},{ }^{154} \mathrm{Eu}, \\
{ }^{234} \mathrm{U},{ }^{238} \mathrm{U},{ }^{237} \mathrm{~Np}, \\
{ }^{239} \mathrm{Pu},{ }^{240} \mathrm{Pu},{ }^{241} \mathrm{Am}\end{array}$ \\
\hline
\end{tabular}





\subsection{BOUNDARY DELINEATION}

\subsection{Review of Radiation Dose Units}

Ionizing radiation is photon (including, high-frequency $\mathrm{UV} ; \mathrm{X}$ and gamma rays, and cosmic radiation) and alpha- and beta-particle emissions of sufficiently high energy (e.g., $\geq 34 \mathrm{eV})$ that they interact with the atoms composing matter, stripping orbital electrons, and creating ion pairs. When ionizing radiation penetrates cells, it deposits energy and directly ionizes biological materials in this manner, and it can also create toxic agents from the ionization of cellular water molecules, such as free radicals and hydrogen peroxide. Even at low doses, radiation is considered to pose some likelihood of lifetime excess cancer risk (i.e., a stochastic effect), which can be quantitatively equated to either morbidity (defined as fatal and nonfatal cancers) or mortality (defined as fatal cancers only).

The activity of a radioactive isotope (i.e., radionuclide) is defined as the number of atomic transformations per second. One atom transformed per second is equal to 1 Becquerel $(\mathrm{Bq}$, in International System of Units, SI), and $3.7 \times 10^{10} \mathrm{~Bq}$ equates to $1 \mathrm{Curie}(\mathrm{Ci}$, the special unit of activity used before SI units were adopted). However, a Bq of activity does not necessarily equate to the number of radiations emitted by the radioactive isotope as it decays. For example, tritium $\left({ }^{3} \mathrm{H}\right)$ releases $1 \beta$ particle per atom transformed (i.e., 1 radiation/s) but cobalt- $60\left({ }^{60} \mathrm{Co}\right)$ releases $1 \beta$ particle and $2 \gamma$ rays per atom transformed (i.e., 3 radiations/s), and potassium-42 $\left({ }^{42} \mathrm{~K}\right)$ releases $1 \beta$ particle and $0.2 \gamma$ rays per atom transformed (i.e., 1.2 radiations $\left./ \mathrm{s}\right)$.

Because activity measures the quantity of atomic transformations per second for a radionuclide, and atomic transformations release ionizing radiation, it is the activity and not the mass of a radioactive isotope that is relevant for assessing health risk. Yet, modeling groundwater flow and radionuclide transport involves accounting for the mass of a radionuclide per unit volume of water (concentration). Specifically, unclassified transport simulations are performed using a unit mass. In this way, one can perform the majority of the calculations in an unclassified environment and then transform the results based on the classified source term in a classified environment. The mass of a radionuclide of concern per unit volume of water can be converted to its activity per unit volume of water (i.e., activity concentration) using the specific activity (SA) for that radionuclide.

The specific activity $(S A)$ is the relationship between mass (e.g., mole) and activity $(\mathrm{Bq})$ for a radionuclide, such that $S A=\lambda \mathrm{N}[\mathrm{Bq} / \mathrm{mole}]$, where the decay constant $(\lambda)$ is expressed as $1 /$ seconds, and equals $0.693 / t_{1 / 2}$, and $t_{1 / 2}$ is the half life of the radionuclide (and conversely $t_{1 / 2}=0.693 / \lambda$ ), which is the time for one-half of the parent atoms that are present for a radionuclide to decay to daughter products (progeny), and $N=$ atoms/mole. Thus, the activity concentration for an individual radionuclide can be determined from its activity using the relationship shown in Equation (4.1):

$$
B q(\text { atoms transformed } / s)=\frac{\text { Mole }}{\left[\frac{0.693}{t_{1 / 2}(s)} \times \frac{6.023 \times 10^{23} \text { atoms }}{\text { mole }}\right]}
$$

Accordingly, knowing the normalized mass per unit volume in water (i.e., from the unclassified transport simulations), the half life, the source mass, and the atomic weight for a 
radionuclide, the unclassified simulation results can be converted to classified activity concentrations for that radionuclide. Then, that value can be used to evaluate health effects from exposure to the radiation emitted by the radionuclides of concern in the water.

The absorbed dose from exposure to ionizing radiation is expressed in units of gray (Gy, in SI units), where $1 \mathrm{~Gy}$ is defined as the energy per unit mass imparted to matter equal to $1 \mathrm{~J} / \mathrm{kg}$ [and it is also equal to $100 \mathrm{rad}$, where rad is the International Commission on Radiation Units and Measurements (ICRU) special dimension used before SI units were adopted]. The dose equivalent is the product of the absorbed dose and a dimensionless radiation quality or weighting factor $(\mathrm{Q}$, representing an adjustment factor for distinguishing between the biological effectiveness of different types of radiation; for example, $Q=1$ for beta, gamma, and X-ray emissions, and $\mathrm{Q}=20$ for alpha emissions) and expressed in units of sievert (Sv), where $1 \mathrm{~Sv}$ represents the energy per unit mass imparted to biological material equal to $1 \mathrm{~J} / \mathrm{kg}$ (and it is also equal to $100 \mathrm{rem}$, where rem is the ICRU special dimension used before SI units were adopted). The effective dose equivalent (ede) is a concept for converting internal exposures to an equivalent whole-body dose (by summing the products of tissue-weighting factors and equivalent doses to an organ) so that doses from internal exposures can be added to those from external exposures to determine a total dose (see Moeller, 1992). The ede also is expressed in units of Sv, and the tissue weighting factor represents the fractional contribution that an individual body organ can make, as a consequence of internal exposure to radiation, to the total lifetime excess cancer risk were the entire body (i.e., all organs) to be irradiated uniformly (EPA, 1988).

To account for dose that is being delivered to tissue(s) as long as a radionuclide is present inside the body and decaying, the committed effective dose equivalent (CEDE) was conceived. This derived value is also expressed in Sv, and is defined as the sum of all doses projected to be received in the future from the intake of radionuclides in the current year, and by convention, the period over which a dose is considered committed in a tissue is $50 \mathrm{y}$ following intake, a value originally selected arbitrarily for application to occupational exposures (EPA, 1988).

The CEDE agrees with modern metabolic and dosimetric understanding, and the CEDE per unit intake (Sv/Bq), or CEDE applicable "dose conversion factor," for internal exposure by ingestion, has been calculated and published by EPA (1988) and can be used to establish intake and concentration guidance in a regulatory context. Such application is considered appropriate because for radionuclides with long effective half lives (i.e., long radioactive half lives in combination with a long residence time in the body, especially relative to a 50-y period of commitment or even a 70-y lifetime), the CEDE may overestimate the total dose that actually would be expected to occur over the 50-y commitment period (Moeller, 1992), or by implication, even a 70-y lifetime.

In contrast with using the CEDE approach for deriving intake and concentration limits for radionuclides, there is another outdated method that is not as valid, but has regulatory precedent. For example, the National Primary Drinking Water Regulations for radionuclides (EPA 2000a) identify $0.04 \mathrm{mSv} / \mathrm{y}(4 \mathrm{mrem} / \mathrm{y})$ as the total annual dose equivalent to an organ or the whole body that cannot be exceeded from internal exposure to beta particle and photon radioactivity, and then this annual dose equivalent, along with a $2 \mathrm{~L} / \mathrm{d}$ consumption rate, is used as a basis for setting annual average activity-concentration limits for drinking water intake for beta-particleand photon-emitting radionuclides (see EPA, 1976, for procedure). This method is best described 
as the "critical-organ dose-limit approach" because it simply involves using an acceptable dose limit for a critical organ as a fundamental parameter for setting a concentration limit.

Today, a far superior and more defensible procedure exists as an alternative to using the "critical-organ dose-limit approach," or even applying CEDE dose conversion factors, for developing concentration limits for radionuclides. This new procedure capitalizes on the development of radionuclide-specific lifetime radiogenic cancer risk coefficients [expressed as either a cancer mortality (fatal only) risk per unit activity or as a cancer morbidity (fatal and nonfatal combined) risk per unit activity (i.e., mortality risk/Bq or morbidity risk/Bq)] for the U.S. population published by EPA (1999), and derived using “ ... state-of-the-art methods and models that take into account age and gender dependence of intake, metabolism, dosimetry, radiogenic risk, and competing causes of death in estimating the risks to health from internal or external exposure to radionuclides." Furthermore, according to EPA (1999), the purpose of these cancer risk coefficients is intended " ... to support rulemaking ..." and " ... encouraged to promote consistency in risk assessment ..." especially by federal agencies.

In fact, the published cancer risk coefficients are suited for use in prospective assessments of potential cancer risk related to long-term exposure to radionuclides in environmental media. Specifically, they have been tabulated for over 800 radionuclides individually (not categorically, as is done for MCLs, which also only address dose and not risk) and include values applicable to low-acute doses or low-dose rates from internal exposure through various media, including drinking water. Technically, these radionuclide-specific cancer-risk coefficients can be applied to estimate the lifetime excess mortality or morbidity cancer risk due to chronic exposure over a lifetime to a constant environmental activity concentration by an average individual in a stationary population in the U.S. Consequently, summing the products of drinking water activity concentrations predicted for specific radionuclides $(\mathrm{Bq} / \mathrm{L})$, a corresponding radionuclide-specific cancer-risk coefficient (e.g., to be exhaustive, cancer morbidity risk/Bq), and a conservative estimation of a lifetime exposure to drinking water (e.g., $2 \mathrm{~L} / \mathrm{d} \times 365 \mathrm{~d} / \mathrm{y} \times 70 \mathrm{y} /$ lifetime), will yield a total lifetime excess cancer risk (in this example, cancer morbidity risk) for exposure to all of the radionuclides considered.

The computed total lifetime excess cancer risk can then be compared to a de facto, "de minimus" level of risk (i.e., so low it can be considered negligible) that can be selected from the lower range of risk identified by EPA as reasonable for establishing regulatory standards for drinking water contaminants [i.e., an excess lifetime cancer risk that does not exceed $10^{-4}$ $(1 / 10,000)$ and ideally is less than $\left.10^{-6}(1 / 1,000,000)\right]$. For example, limiting lifetime excess cancer morbidity risk to $10^{-6}$ or less would be a legitimate unifying consideration with regard to establishing a reasonably well-conceived health-protective contaminant boundary perimeter for a CAU.

Finally, a systematic quantitative uncertainty analysis, using either the full complex computational risk-coefficient model, or even a simpler abstraction, is a difficult task due to the large number of parameters and radionuclides (EPA, 1999). For this reason, the risk coefficients are taken as a group to be centrally located within their uncertainty range, even though this may not always be true for some individual radionuclide-specific cancer-risk coefficients (EPA, 1999). Application of the published tabulated individual radionuclide-specific cancer-risk coefficients can be expected to conform to accepted regulatory practice and produce results that would be considered sufficient. Therefore, this document will focus on the use of the published 
radionuclide-specific cancer-risk coefficients without addressing the quantification of uncertainty related to the risk factors.

\subsection{Risk-based Analysis}

One metric for determining the extent of contaminant boundaries is morbidity cancer risk. Morbidity cancer risk is the most exhaustive endpoint, as it addresses both fatal and nonfatal cancers. EPA (2000a) identified an excess lifetime cancer risk that does not exceed $10^{-4}$ $(1 / 10,000)$ and ideally less than $10^{-6}(1 / 1,000,000)$ as a reasonable basis for establishing regulatory standards, and thus this range can represent a "de minimus" level of risk (i.e., so low it can be considered negligible). For purposes of this document, limiting lifetime excess cancer morbidity risk to $10^{-6}$ will be used as the limit of lifetime excess cancer morbidity risk for establishing the perimeter of a contaminant boundary for a CAU. The following strategy explains the procedure for calculating such a boundary.

The parameters that define radionuclide-specific risk calculations are:

1. Radionuclide activity concentration $\left[c_{i}(x, t)\right]$

2. Ingestion exposure rate $[E]$

3. Average life duration $[D]$

4. The applicable radionuclide-specific morbidity cancer-risk coefficient $\left[r_{i}\right]$

The radionuclide activity concentration is derived from the flow and transport simulations and it is assumed that the majority of the uncertainty in the risk calculation is derived from this parameter. The ingestion exposure rate (2 L/day) and average life duration (70 years) are expected values as determined by EPA (1999). The morbidity cancer-risk coefficients are derived by EPA (1999) and are shown in Table 4.1. It is important to note that risk coefficients are not available for argon-39, krypton-85 and gadolinium-150 and as such, cancer risk cannot be calculated for these radionuclides.

The risk $(\mathrm{R}(\mathrm{x}, \mathrm{t}))$ is calculated as:

$$
R(x, t)=\sum_{i=1}^{n} c_{i}(x, t)(E)(D)\left(r_{i}\right)
$$

where $c_{i}(x, t)$ is the activity concentration for a radionuclide at a given position $\mathrm{x}$ and time $\mathrm{t}$ $(\mathrm{pCi} / \mathrm{L}), E$ is the ingestion exposure rate $(\mathrm{L} / \mathrm{D}), D$ is the average life duration (days), and $r_{i}$ is the risk coefficient for radionuclide $i$.

Equation (4.2) is computed with the assumption that the activity concentration of a radionuclide in the environmental medium is constant over the entire lifetime of the exposed population. This assumption can be addressed in one of two ways. In aquifers with relatively low velocities, the concentrations can be collected from the transport model at 70-year intervals. Aquifers that exhibit rapid velocities require time averaging as:

$$
\bar{c}_{i}(x, t)=\int_{j}^{j+70} c_{i}(x, t)
$$


Table 4.1. The morbidity cancer-risk coefficients as derived by EPA (1999) and half-lives for 52 radionuclides. Note that risk coefficients are not available for argon-39, krypton-85, and gadolium-150.

\begin{tabular}{|c|c|c|c|}
\hline Radionuclide & Isotope Symbol & Half life $\left(\mathrm{t}_{1 / 2} ; \mathrm{y}\right)$ & Risk/pCi \\
\hline Tritium & $\mathrm{H}-3$ & $1.23 \mathrm{E}+01$ & $5.07 \mathrm{E}-14$ \\
\hline Carbon-14 & $\mathrm{C}-14$ & $5.73 \mathrm{E}+03$ & $1.55 \mathrm{E}-12$ \\
\hline Sodium-22 & $\mathrm{Na}-22$ & $2.61 \mathrm{E}+00$ & $9.62 \mathrm{E}-12$ \\
\hline Aluminum-26 & Al-26 & $7.30 \mathrm{E}+05$ & $1.73 \mathrm{E}-11$ \\
\hline Chlorine-36 & $\mathrm{Cl}-36$ & $3.01 \mathrm{E}+05$ & $3.30 \mathrm{E}-12$ \\
\hline Argon-39 & Ar-39 & $2.69 \mathrm{E}+02$ & $\mathrm{n} / \mathrm{a}$ \\
\hline Potassium-40 & $\mathrm{K}-40$ & $1.28 \mathrm{E}+09$ & $2.47 \mathrm{E}-11$ \\
\hline Calcium-41 & $\mathrm{Ca}-41$ & $1.03 \mathrm{E}+05$ & $3.53 \mathrm{E}-13$ \\
\hline Manganese-54 & $\mathrm{Mn}-54$ & $8.55 \mathrm{E}-01$ & $2.28 \mathrm{E}-12$ \\
\hline Cobalt- 60 & Co-60 & $5.27 \mathrm{E}+00$ & $1.57 \mathrm{E}-11$ \\
\hline Nickel-59 & $\mathrm{Ni}-59$ & $7.60 \mathrm{E}+04$ & $2.74 \mathrm{E}-13$ \\
\hline Nickel-63 & $\mathrm{Ni}-63$ & $1.00 \mathrm{E}+02$ & $6.70 \mathrm{E}-13$ \\
\hline Krypton-85 & $\mathrm{Kr}-85$ & $1.07 \mathrm{E}+01$ & $\mathrm{n} / \mathrm{a}$ \\
\hline Strontium-90 & Sr-90 & $2.91 \mathrm{E}+01$ & $5.59 \mathrm{E}-11$ \\
\hline Zirconium-93 & Zr-93 & $1.50 \mathrm{E}+06$ & $1.11 \mathrm{E}-12$ \\
\hline Niobium-93m & $\mathrm{Nb}-93 \mathrm{~m}$ & $1.61 \mathrm{E}+01$ & $8.03 \mathrm{E}-13$ \\
\hline Niobium-94 & $\mathrm{Nb}-94$ & $2.00 \mathrm{E}+04$ & 7.77E-12 \\
\hline Technetium-99 & Tc-99 & $2.13 \mathrm{E}+05$ & $2.75 \mathrm{E}-12$ \\
\hline Ruthenium-106 & $\mathrm{Ru}-106$ & $1.02 \mathrm{E}+00$ & $4.22 \mathrm{E}-11$ \\
\hline Palladium-107 & Pd-107 & $6.50 \mathrm{E}+06$ & $2.50 \mathrm{E}-13$ \\
\hline Cadmium-113m & $\mathrm{Cd}-113 \mathrm{~m}$ & $1.41 \mathrm{E}+01$ & $2.87 \mathrm{E}-11$ \\
\hline Tin- $121 \mathrm{~m}$ & $\mathrm{Sn}-121 \mathrm{~m}$ & $5.50 \mathrm{E}+01$ & $2.34 \mathrm{E}-12$ \\
\hline Tin-126 & Sn-126 & $1.00 \mathrm{E}+05$ & $2.56 \mathrm{E}-11$ \\
\hline Antimony-125 & $\mathrm{Sb}-125$ & $2.76 \mathrm{E}+00$ & $4.37 \mathrm{E}-12$ \\
\hline Iodine-129 & I-129 & $1.57 \mathrm{E}+07$ & $1.48 \mathrm{E}-10$ \\
\hline Cesium-134 & Cs-134 & $2.07 \mathrm{E}+00$ & $4.22 \mathrm{E}-11$ \\
\hline Cesium-135 & Cs-135 & $2.30 \mathrm{E}+06$ & $4.74 \mathrm{E}-12$ \\
\hline Cesium-137 & Cs-137 & $3.02 \mathrm{E}+01$ & $3.04 \mathrm{E}-11$ \\
\hline Cerium-144 & $\mathrm{Ce}-144$ & $7.80 \mathrm{E}-01$ & $3.52 \mathrm{E}-11$ \\
\hline Samarium-151 & Sm-151 & $9.00 \mathrm{E}+01$ & $5.55 \mathrm{E}-13$ \\
\hline Europium-150 & $\mathrm{Eu}-150$ & $3.60 \mathrm{E}+01$ & $4.33 \mathrm{E}-12$ \\
\hline Europium-152 & $\mathrm{Eu}-152$ & $1.35 \mathrm{E}+01$ & $6.07 \mathrm{E}-12$ \\
\hline Europium-154 & Eu-154 & $8.59 \mathrm{E}+00$ & $1.03 \mathrm{E}-11$ \\
\hline Europium-155 & $\mathrm{Eu}-155$ & $4.71 \mathrm{E}+00$ & $1.90 \mathrm{E}-12$ \\
\hline Gadolinium-150 & Gd-150 & $1.80 \mathrm{E}+06$ & $\mathrm{n} / \mathrm{a}$ \\
\hline Holmium-166m & $\mathrm{Hm}-166 \mathrm{~m}$ & $1.20 \mathrm{E}+03$ & $8.03 \mathrm{E}-12$ \\
\hline Thorium-232 & Th-232 & $1.40 \mathrm{E}+10$ & $1.01 \mathrm{E}-10$ \\
\hline Uranium-232 & $\mathrm{U}-232$ & $7.00 \mathrm{E}+01$ & $2.92 \mathrm{E}-10$ \\
\hline Uranium-233 & U-233 & $1.59 \mathrm{E}+05$ & $7.18 \mathrm{E}-11$ \\
\hline Uranium-234 & U-234 & $2.46 \mathrm{E}+05$ & 7.07E-11 \\
\hline Uranium-235 & $\mathrm{U}-235$ & $7.04 \mathrm{E}+08$ & $6.96 \mathrm{E}-11$ \\
\hline Uranium-236 & U-236 & $2.34 \mathrm{E}+07$ & $6.70 \mathrm{E}-11$ \\
\hline Uranium-238 & $\mathrm{U}-238$ & $4.47 \mathrm{E}+09$ & $6.40 \mathrm{E}-11$ \\
\hline Neptunium-237 & $\mathrm{Np}-237$ & $2.14 \mathrm{E}+06$ & $6.18 \mathrm{E}-11$ \\
\hline Plutonium-238 & $\mathrm{Pu}-238$ & $8.77 \mathrm{E}+01$ & $1.31 \mathrm{E}-10$ \\
\hline Plutonium-239 & $\mathrm{Pu}-239$ & $2.41 \mathrm{E}+04$ & $1.35 \mathrm{E}-10$ \\
\hline Plutonium-240 & $\mathrm{Pu}-240$ & $6.56 \mathrm{E}+03$ & $1.35 \mathrm{E}-10$ \\
\hline Plutonium-241 & $\mathrm{Pu}-241$ & $1.44 \mathrm{E}+01$ & $1.76 \mathrm{E}-12$ \\
\hline Plutonium-242 & $\mathrm{Pu}-242$ & $3.75 \mathrm{E}+05$ & $1.28 \mathrm{E}-10$ \\
\hline Americium-241 & Am-241 & $4.33 \mathrm{E}+02$ & $1.04 \mathrm{E}-10$ \\
\hline Americium-243 & Am-243 & $7.37 \mathrm{E}+03$ & $1.03 \mathrm{E}-10$ \\
\hline Curium-244 & $\mathrm{Cm}-244$ & $1.81 \mathrm{E}+01$ & $8.36 \mathrm{E}-11$ \\
\hline
\end{tabular}


where $\bar{c}(x, t)$ is a running average of the activity concentration over a 70 -yr period. Note that it may be necessary to run the simulations to $t=1,070$ years to calculate the running average. In either case, the risk is calculated at $70-\mathrm{yr}$ intervals at all locations $\boldsymbol{x}=(\mathrm{x}, \mathrm{y}, \mathrm{z})$. Thus, based upon the model solution $c_{i}(\mathbf{x}, t), R\left(\mathbf{x}, t_{j}\right)$ can be computed at all discrete locations and at all times of the simulation. The locus of discrete points (or grid blocks) where $R\left(\mathbf{x}, t_{j}\right)$ ever takes on a value greater than $10^{-6}$ would then define a zone of contamination above the health-protective standard with respect to cancer morbidity risk. Conversely, the locus of discrete points where $R\left(\mathbf{x}, t_{j}\right)$ is equal to or less than $10^{-6}$ would define a zone of contamination that is below the healthprotective standard with respect to cancer morbidity risk.

In application, one must account for the uncertainties in the flow and transport model, but Equation (4.2) does not explicitly account for uncertainty. The flow and transport simulations are performed in a Monte Carlo environment, which accounts for the parametric uncertainty inherent in all models. Thus, for each location $\boldsymbol{x}$ and selected time $t$, there will be a distribution of $c_{i}(\mathbf{x}, t)$ and $R\left(\mathbf{x}, t_{j}\right)$ values that need to be evaluated. The probabilistic interpretation (i.e., 95 percent confidence intervals) is calculated to determine the contaminant boundary as described in the uncertainty analysis section below.

\subsection{Regulatory Based Analysis}

Another metric for determining the extent of contaminant boundaries is based on the SDWA standards. This is the metric specified in the FFACO. The regulatory standard is based on three categories of radionuclides:

1. Alpha $(\alpha)$ emitters, excluding uranium

2. $\operatorname{Beta}(\beta)$ and photon emitters

3. Uranium

If one or more of the categorical MCLs is exceeded in the groundwater, then the fluid parcel is considered to exceed the regulatory MCL.

For the alpha-emitting radionuclides (i.e., ${ }^{238} \mathrm{Pu}$, and ${ }^{241} \mathrm{Am}$ ), the sum of the activity concentrations of alpha-emitting radionuclides is calculated and compared to the $15 \mathrm{pCi} / \mathrm{L}$ standard. If the fluid parcel exceeds the $15 \mathrm{pCi} / \mathrm{L}$ standard, then the MCL for this fluid parcel is assumed to be violated.

For the $\beta$ - and photon-emitting radionuclides, such as ${ }^{3} \mathrm{H}$ (tritium), ${ }^{90} \mathrm{Sr},{ }^{129} \mathrm{I}$, and ${ }^{137} \mathrm{Cs}$, a "sum-of-the-fractions" procedure is involved (see EPA, 2000c). First, simulated $\beta$ - and photonemitting radionuclides are determined. A conversion table is then created (by procedures described in EPA, 1976), or consulted (see Huber, 2001, who applied the methodology described in EPA, 1976) to determine the activity concentration corresponding to an annual dose equivalent of $4 \mathrm{mrem} / \mathrm{y}$ for each of the $\beta$ - and photon-emitting radionuclides for which an activity concentration is predicted. Next, each radionuclide-specific $\beta$ value $(e . g$., $\mathrm{pCi} / \mathrm{L})$ is divided by the activity concentration $(e . g ., \mathrm{pCi} / \mathrm{L})$ equivalent to the annual dose equivalent of $4 \mathrm{mrem} / \mathrm{y}$ for that particular radionuclide. This fraction represents the contribution of this radionuclide to the maximum allowable $4 \mathrm{mrem} / \mathrm{y}$ limit for all $\beta$ and photon emitters present. These fractions are then summed for all beta and photon emitters for each fluid parcel (i.e., finite 
difference cell within the model domain). If the sum exceeds unity, then the location is assumed to exceed the MCL.

For uranium isotopes, the sum of mass concentrations of uranium isotopes (i.e., $\mu \mathrm{g} / \mathrm{L}$ ) present at each location is calculated. If the sum of mass concentrations exceeds the MCL for uranium $(30 \mu \mathrm{g} / \mathrm{L})$, then the MCL is violated.

The categorical MCL evaluations are determined at every location in the model domain at 70 -yr intervals, which represents the mean lifetime expectancy. The probabilistic interpretation (i.e., 95 percent confidence intervals) is calculated to determine the contaminant boundary as described in the uncertainty analysis section below.

\subsection{Uncertainty Analysis}

If there were no uncertainty in the solute transport model, the risk-based or regulatory based analysis would provide explicit definition of the boundary maps. In reality though, the groundwater models contain a certain degree of uncertainty, which needs to be represented in an analysis of the boundary delineation. This was recognized in the FFACO and expressed as a requirement that the contaminant boundary be predicted at a 95 percent level of confidence. This requirement can actually be interpreted in two different, but complementary, ways to map the three-dimensional extent where groundwater has been contaminated and the associated uncertainty. One approach is to identify the region in which there is 95 percent certainty that contaminants exist and exceed the health risk or regulatory threshold. The boundary will then encircle the region that meets this criterion. The alternative approach is to identify the region where there is 95 percent certainty that contaminants do not pose a health risk and therefore encompasses the region that fails to meet the boundary criterion. In other words, the water that does not pose a health risk is external to the region enclosed by the boundary.

Although the differences in calculation between these two approaches to computing a contaminant boundary may appear subtle, they are dramatically different in terms of their interpretation. The first approach provides an area in which there is a high degree of certainty that risk values are not lower than the calculated value, while the second approach provides an area in which there is a low probability that one will exceed a specified risk.

These two types of boundaries are a direct result of the uncertainty analysis, but with different perspectives: contaminated zone versus uncontaminated zone. The approaches are statistical complements of one another: a boundary predicted by the model to have a 95 percent level of confidence in encompassing the contaminant is also the boundary where there is a 5 percent assurance that the water external to it is clean, and a boundary encompassing an area that has a 5 percent confidence level that it contains the contaminant, has a 95 percent certainty that the area external is clean. The two approaches yield the same result if a 50 percent significance level is chosen. The description of the boundary in Appendix VI of the FFACO (as presented in the Introduction) is ambiguous as to which of these two perspectives should be used for the contaminant boundary. The approach presented here follows the second alternative, identifying the region where there is a 95 percent certainty that contaminants do not pose a health risk.

The uncertainty in the groundwater flow and transport model is handled directly within a Monte Carlo-type approach. Monte Carlo methods describe the uncertainty in model predictions based upon an analysis of the uncertainty in model input parameters. Bayesian methods are used in combination with Monte Carlo techniques to weight each Monte Carlo realization based on its 
ability to reproduce observed system behavior. The Bayesian methods (see Section 2.2.6) allow one to "calibrate" the stochastic model within the framework of the uncertainty analysis.

The general approach to quantify the model uncertainty is described by the following steps:

1. Determine all model parameters that are considered uncertain. It is important to note that uncertainty is derived from parameter measurement errors, spatial heterogeneity, and errors in model conceptualization each of which can be included in the uncertainty analysis.

2. Quantify the distributions of all uncertain parameters. This is typically done via a specification of a probability distribution function (pdf) for each parameter.

3. Perform numerical simulation of groundwater flow and transport with randomly sampled parameter distributions.

4. Calculate the likelihood function (e.g., weights) for each realization. According to Equation (2.5), the likelihood function is a measure of the "fit" between simulated and observed system behavior. Typically, hydraulic heads are used as the basis for calculating the likelihood measure.

5. Quantify the pdf for the simulated solute transport. In the context of calculating boundary maps, a pdf of a risk-metric is created for each location in the model domain at 70-yr intervals. The pdf takes the form of probability exceedence of the $10^{-6}$ risk threshold for the risk-based approach.

6. Determine the 95 percent confidence threshold for the contaminant boundary.

Steps 1 through 4 are described in sections 2.0 and 3.0 and the details of the pdf analysis and associated confidence thresholds (i.e., steps 5 and 6) are provided below.

It is important to note that the groundwater flow and transport simulations provide predictions of radionuclide transport under ambient conditions. The boundary maps are determined based upon an assumption that a human may become exposed to contaminated groundwater by drinking the groundwater at a rate of $2 \mathrm{~L} /$ day. Although a rate of $2 \mathrm{~L} /$ day is small, access to groundwater would typically be from a standard domestic well which, according to Nevada Law, can pump up to 1,800 gallons/day ( 2,500 $\mathrm{m}^{3} /$ day). In most situations, domestic well pumping will not have a large impact on the rate and/or direction in which contaminants move, but under certain situations, this may not be the case. The appendix presents an analysis of the impact of well pumping on solute transport behavior. The delineation of the contaminant boundary may be dependent on the pumping regime and may require further investigation if someone wants to utilize the groundwater resources adjacent to the nuclear test.

The quantification of the pdf for the risk-based analysis utilizes the results of the solute transport model and the source mass for individual radionuclides to determine if a fluid parcel exceeds a $10^{-6}$ risk threshold with the inclusion of model uncertainty. The risk-based approach yields a continuous pdf for each spatial position at 70-yr intervals. Although the statistical analysis presented herein is for a risk-based boundary, the analysis is similar for a regulatory based boundary.

A confidence interval defines a range of risk values for a given significance level (e.g., 95 percent), which describes the magnitude of the uncertainty inherent in the numerical model. A typical confidence region as defined by statisticians is given by: 


$$
\int_{a}^{b} f(x)=\gamma
$$

where $\mathrm{f}(\mathrm{x})$ is the pdf, $\gamma$ is the significance level and $a$ and $b$ are the lower and upper bounds of the confidence region (i.e., confidence levels). Figure 4.1 is a graphical representation of this type of definition. The dashed region represents an area equal to $\gamma$. This type of definition captures the central portion of the pdf, which is not appropriate for the definition of boundary maps, as the tails represent very high risk and very low risk values.

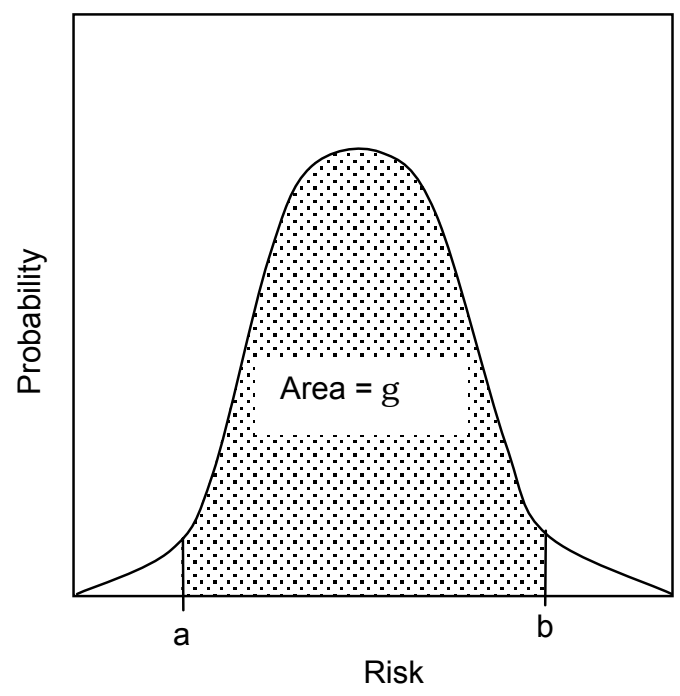

Figure 4.1. Probability distribution function showing how typical confidence levels are determined.

For the purposes of contaminant boundaries, the choice is made to focus on the region of "clean" water and as such, the lower end (i.e., uncontaminated region) of the pdf is used in the determination of the confidence threshold:

$$
\int_{1}^{a_{1}} f(x)=\gamma
$$

where $a_{1}$ is the threshold risk value that captures an area of size $\gamma$. Figure 4.2 shows a graphical representation of the proposed contaminant boundary confidence threshold. The contaminant definition captures all transport realizations with risk values greater than $a_{1}$ and determines the threshold risk value that captures our knowledge to a level equal to $\gamma$. If for example a $\gamma$ was chosen at a 95 percent level, then the threshold value represents a risk value in which there is 95 percent confidence that the risk value is less than or equal to $a_{1}$. 


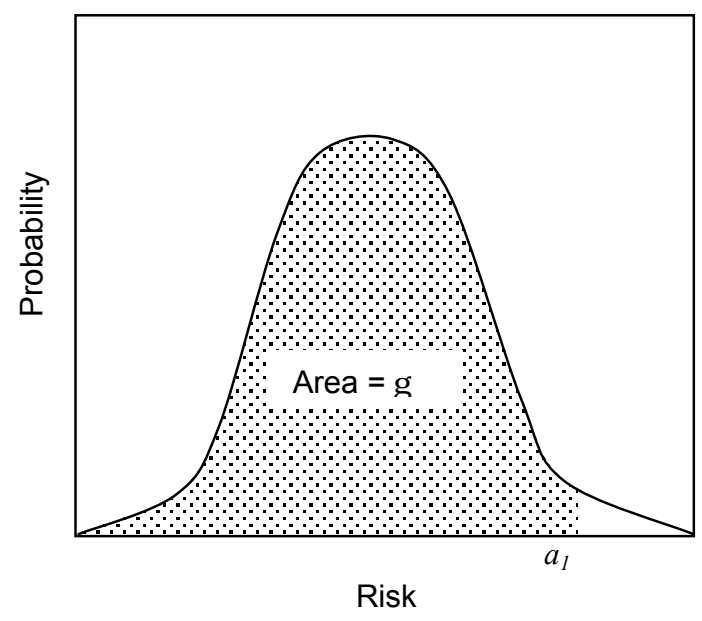

Figure 4.2. Probability distribution function showing how the risk threshold is calculated for the contaminant boundary.

The boundary maps are created by determining the threshold risk value for individual locations at 70-yr intervals.. The weighted risk values (i.e., the probabilities incorporate the Bayesian likelihoods) are used to create a pdf of risk. The threshold risk value is determined as shown in Figure 4.3. If the risk threshold is less than or equal to $10^{-6}$, or the MCL of any category is not exceeded at the 95 percent level, then the location is considered to be external to the contaminant boundary. This process is repeated for all locations within the model domain. All cells that did not meet the above criterion define the contaminant boundary region. Therefore, the contaminant boundary is a three-dimensional surface that encloses all cells that have a risk threshold greater than $10^{-6}$ (or cells that violate the MCL). The boundary maps will be presented in three two-dimensional sections representing the $x-y, x-z$, and $y-z$ Cartesian planes. The boundary sections are two-dimensional projections of the three-dimensional boundary surface. For example, the aerial view (x-y plane) represents the maximum extent of the threedimensional boundary or volume as projected to the surface as shown in Figure 4.4. A location is considered to be within the boundary if at any $x-y$ location there is at least one vertical position that is found to be within the boundary. Similar projections are made for the $\mathrm{x}-\mathrm{z}$ and $\mathrm{y}-\mathrm{z}$ planes.

There are two options that are available to present the temporal history of the contaminant boundary. One option is to produce maps that represent an instantaneous view of the boundary for a given 70-yr time interval and the other option is to present the cumulative boundary from time zero to a given time period. The latter option is being proposed for the presentation of all boundary maps, as it represents the maximum extent of the boundary at any given time. 


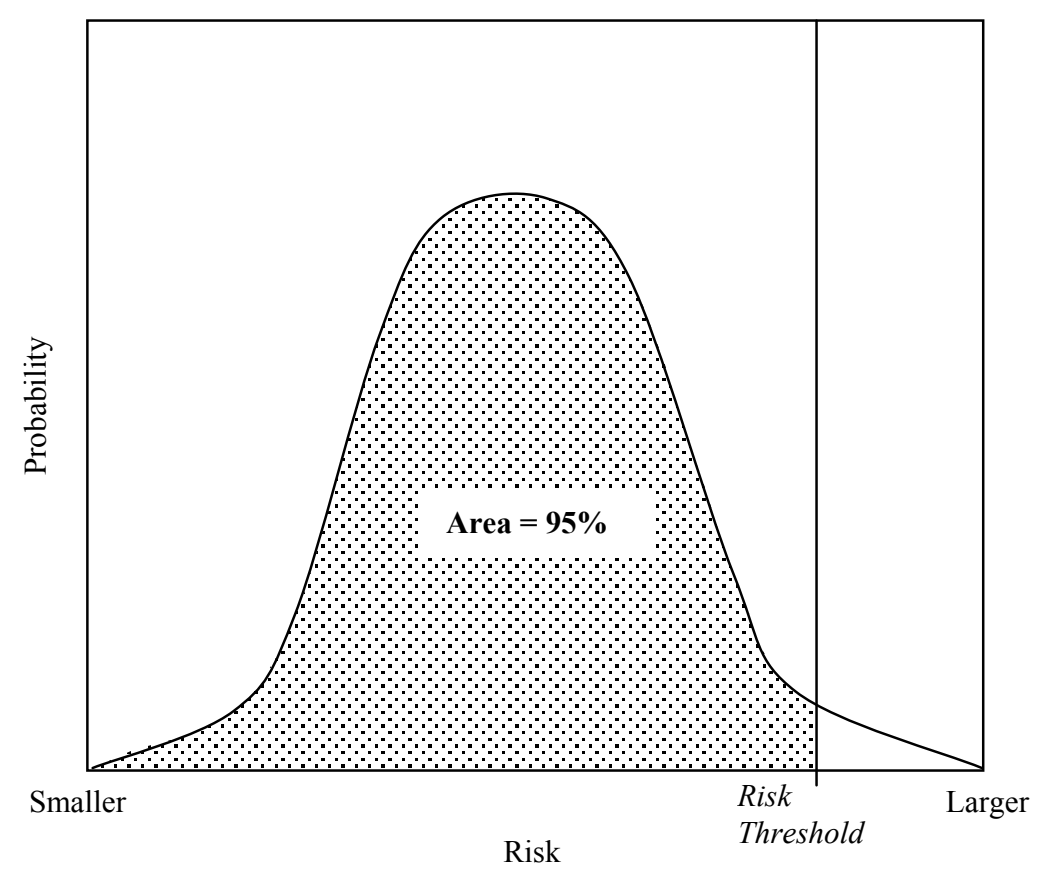

Figure 4.3. An example of the probability distribution function and how the risk threshold is calculated for the contaminant boundary. 


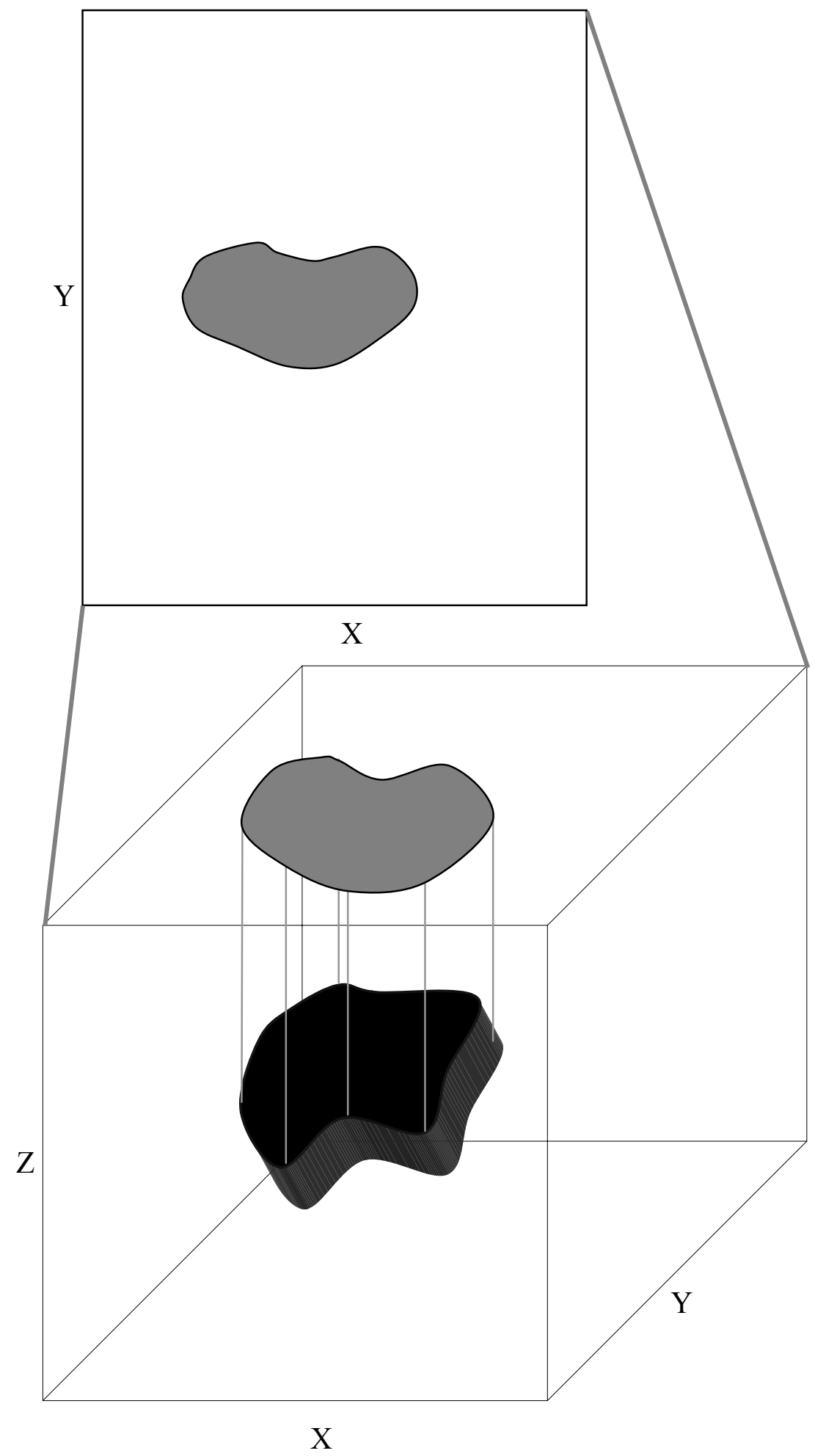

Figure 4.4. An example of a three-dimensional contaminant boundary and the associated mapping to an $\mathrm{x}-\mathrm{y}$ cross section. 


\subsection{HYPOTHETICAL EXAMPLE}

The methodologies presented above are applied to a hypothetical groundwater flow system for evaluation. The use of a hypothetical example allows one to test the methodology on a groundwater system in which one can ensure that transport is occurring.

The hypothetical flow system is constructed as shown in Figure 5.1. A Gaussian hydraulic conductivity field is used with the mean adjusted such that conservative solutes move on average two-thirds of the distance from the source to the downgradient end of the model domain. Six transport classes were simulated to represent the different combinations of hydraulic/puddle glass release and geochemical sorption. The transport parameters used are shown in Table 5.1 and are analogous to values used for other modeling studies of radionuclide transport (Pohlmann et al., 1999). An unclassified source term mass as derived from the average of Area 19 and 20 tests located on the Nevada Test Site is used for this hypothetical case (Smith, 2001). Thirty-nine (39) radionuclides are simulated because source masses were not available for the entire set. Risk calculations were performed on all 39 radionuclides, but only 31 were included in the regulatory based analysis, as MCLs are not available for the entire set (Table 5.2). A total of 100 realizations were simulated to assess the impact of uncertainty of hydraulic conductivity spatial variability on the determination of contaminant boundary maps. Although other section maps can be calculated, only aerial boundary maps are presented for the hypothetical simulations.

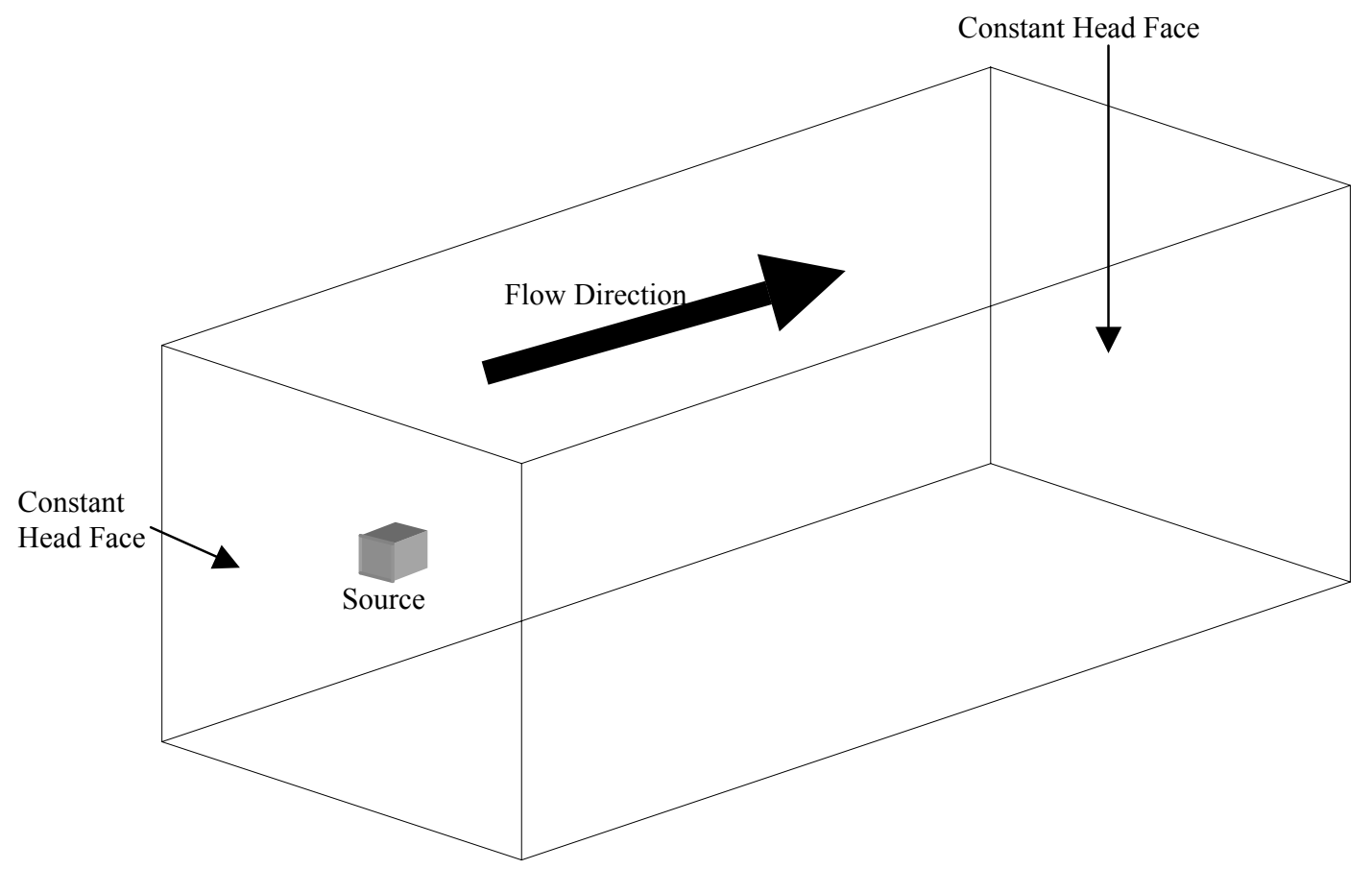

Figure 5.1. Three-dimensional depiction of the hypothetical groundwater flow and transport model. 
Table 5.1. Ratio of hydraulic versus glass release, retardation coefficients, and an example isotope as used in the hypothetical solute transport model.

\begin{tabular}{ccccccc}
\hline Class & 1 & 2 & 3 & 4 & 5 & 6 \\
\hline Hydraulic/Glass Release & $1.0 / 0.0$ & $0.5 / 0.5$ & $0.6 / 0.4$ & $0.05 / 0.95$ & $0.8 / 0.2$ & $0.05 / 0.95$ \\
Retardation & 1 & 1 & 10 & 1 & 10 & 100 \\
Example & ${ }^{3} \mathrm{H}$ & ${ }^{129} \mathrm{I}$ & ${ }^{90} \mathrm{Sr}$ & ${ }^{99 \mathrm{~g}} \mathrm{Tc}$ & ${ }^{137} \mathrm{Cs}$ & ${ }^{234} \mathrm{U}$ \\
\hline
\end{tabular}

Table 5.2. Radionuclides, transport class, half life, source activity, risk factor, emission type, and MCL as used in the hypothetical transport model.

\begin{tabular}{|c|c|c|c|c|c|c|c|}
\hline Number & Isotope & Transport Class & $\begin{array}{l}\text { Half Life } \\
\left(\mathrm{t}_{1 / 2} ; \mathrm{y}\right)\end{array}$ & $\begin{array}{c}\text { Source Activity } \\
\text { (Ci) }\end{array}$ & $\begin{array}{c}\text { Risk Factor } \\
\text { (Risk/pCi) }\end{array}$ & $\begin{array}{c}\text { Emission } \\
\text { Type }\end{array}$ & MCL \\
\hline 1 & Tritium & 1 & $1.23 \mathrm{E}+01$ & $9.19 \mathrm{E}+05$ & $5.07 \mathrm{E}-14$ & beta & $20,000 \mathrm{pCi} / \mathrm{L}$ \\
\hline 2 & Carbon-14 & 1 & $5.73 \mathrm{E}+03$ & $7.30 \mathrm{E}+00$ & $1.55 \mathrm{E}-12$ & beta & $2,000 \mathrm{pCi} / \mathrm{L}$ \\
\hline 3 & Aluminum-26 & 1 & $7.30 \mathrm{E}+05$ & $1.18 \mathrm{E}-04$ & $1.73 \mathrm{E}-11$ & beta & not available \\
\hline 4 & Chlorine-36 & 2 & $3.01 \mathrm{E}+05$ & $2.81 \mathrm{E}+00$ & $3.30 \mathrm{E}-12$ & beta & $700 \mathrm{pCi} / \mathrm{L}$ \\
\hline 5 & Calcium-41 & 2 & $1.03 \mathrm{E}+05$ & $2.16 \mathrm{E}+01$ & $3.53 \mathrm{E}-13$ & beta & not available \\
\hline 6 & Cobalt-60 & 2 & $5.27+00$ & $5.24 \mathrm{E}-01$ & $1.57 \mathrm{E}-11$ & beta & $100 \mathrm{pCi} / \mathrm{L}$ \\
\hline 7 & Nickel-59 & 2 & $7.60 \mathrm{E}+04$ & $5.54 \mathrm{E}+01$ & $2.74 \mathrm{E}-13$ & beta & $300 \mathrm{pCi} / \mathrm{L}$ \\
\hline 8 & Strontium-90 & 3 & $2.91 \mathrm{E}+01$ & $1.57 \mathrm{E}+04$ & $5.59 \mathrm{E}-11$ & beta & $8 \mathrm{pCi} / \mathrm{L}$ \\
\hline 9 & Zirconium-93 & 3 & $1.50 \mathrm{E}+06$ & $5.49 \mathrm{E}-01$ & $1.11 \mathrm{E}-12$ & beta & $2,000 \mathrm{pCi} / \mathrm{L}$ \\
\hline 10 & Niobium-93m & 3 & $1.61 \mathrm{E}+01$ & $1.00 \mathrm{E}+02$ & $8.03 \mathrm{E}-13$ & beta & $1,000 \mathrm{pCi} / \mathrm{L}$ \\
\hline 11 & Niobium-94 & 3 & $2.00 \mathrm{E}+04$ & $2.28 \mathrm{E}+00$ & $7.77 \mathrm{E}-12$ & beta & not available \\
\hline 12 & Technetium-99 & 4 & $2.13 \mathrm{E}+05$ & $4.03 \mathrm{E}+00$ & $2.75 \mathrm{E}-12$ & beta & $900 \mathrm{pCi} / \mathrm{L}$ \\
\hline 13 & Palladium-107 & 4 & $6.50 \mathrm{E}+06$ & $2.07 \mathrm{E}-02$ & $2.50 \mathrm{E}-13$ & beta & not available \\
\hline 14 & Cadmium-113m & 4 & $1.41 \mathrm{E}+01$ & $1.53 \mathrm{E}+01$ & $2.87 \mathrm{E}-11$ & beta & not available \\
\hline 15 & Tin- $121 \mathrm{~m}$ & 4 & $5.50 \mathrm{E}+01$ & $5.68 \mathrm{E}+01$ & $2.34 \mathrm{E}-12$ & beta & not available \\
\hline 16 & Tin-126 & 4 & $1.00 \mathrm{E}+05$ & $6.46 \mathrm{E}-01$ & $2.56 \mathrm{E}-11$ & beta & not available \\
\hline 17 & Iodine-129 & 2 & $1.57 \mathrm{E}+07$ & $1.24 \mathrm{E}-02$ & $1.48 \mathrm{E}-10$ & beta & $1 \mathrm{pCi} / \mathrm{L}$ \\
\hline 18 & Cesium-135 & 4 & $2.30 \mathrm{E}+06$ & $4.16 \mathrm{E}-01$ & $4.74 \mathrm{E}-12$ & beta & $900 \mathrm{pCi} / \mathrm{L}$ \\
\hline 19 & Cesium-137 & 5 & $3.02 \mathrm{E}+01$ & $1.99 \mathrm{E}+04$ & $3.04 \mathrm{E}-11$ & beta & $200 \mathrm{pCi} / \mathrm{L}$ \\
\hline 20 & Samarium-151 & 6 & $9.00 \mathrm{E}+01$ & $7.51 \mathrm{E}+02$ & $5.55 \mathrm{E}-13$ & beta & $1,000 \mathrm{pCi} / \mathrm{L}$ \\
\hline 21 & Europium-150 & 6 & $3.60 \mathrm{E}+01$ & $1.46 \mathrm{E}+01$ & $4.33 \mathrm{E}-12$ & beta & not available \\
\hline 22 & Europium-152 & 6 & $1.35 \mathrm{E}+01$ & $4.32 \mathrm{E}+02$ & $6.07 \mathrm{E}-12$ & beta & $200 \mathrm{pCi} / \mathrm{L}$ \\
\hline 23 & Europium-154 & 6 & $8.59 \mathrm{E}+00$ & $2.04 \mathrm{E}+02$ & $1.03 \mathrm{E}-11$ & beta & $60 \mathrm{pCi} / \mathrm{L}$ \\
\hline 24 & Holmium-166m & 6 & $1.20 \mathrm{E}+03$ & $5.89 \mathrm{E}-01$ & $8.03 \mathrm{E}-12$ & beta & $90 \mathrm{pCi} / \mathrm{L}$ \\
\hline 25 & Uranium-232 & 6 & $7.00 \mathrm{E}+01$ & $3.35 \mathrm{E}+00$ & $2.92 \mathrm{E}-10$ & alpha \& uranium & $30 \mathrm{mg} / \mathrm{L}$ \\
\hline 26 & Uranium-233 & 6 & $1.59 \mathrm{E}+05$ & $2.25 \mathrm{E}+00$ & $7.18 \mathrm{E}-11$ & alpha \& uranium & $30 \mathrm{mg} / \mathrm{L}$ \\
\hline 27 & Uranium-234 & 6 & $2.46 \mathrm{E}+05$ & $1.62 \mathrm{E}+00$ & $7.07 \mathrm{E}-11$ & alpha \& uranium & $30 \mathrm{mg} / \mathrm{L}$ \\
\hline 28 & Uranium-235 & 6 & $7.04 \mathrm{E}+08$ & $2.18 \mathrm{E}-02$ & $6.96 \mathrm{E}-11$ & alpha \& uranium & $30 \mathrm{mg} / \mathrm{L}$ \\
\hline 29 & Uranium-236 & 6 & $2.34 \mathrm{E}+07$ & $6.22 \mathrm{E}-02$ & $6.70 \mathrm{E}-11$ & alpha \& uranium & $30 \mathrm{mg} / \mathrm{L}$ \\
\hline 30 & Uranium-238 & 6 & $4.47 \mathrm{E}+09$ & $2.89 \mathrm{E}-02$ & $6.40 \mathrm{E}-11$ & alpha \& uranium & $30 \mathrm{mg} / \mathrm{L}$ \\
\hline 31 & Neptunium-237 & 6 & $2.14 \mathrm{E}+06$ & 4.81E-01 & $6.18 \mathrm{E}-11$ & alpha & $15 \mathrm{pCi} / \mathrm{L}$ \\
\hline 32 & Plutonium-238 & 6 & $8.77 \mathrm{E}+01$ & $9.43 \mathrm{E}+01$ & $1.31 \mathrm{E}-10$ & alpha & $15 \mathrm{pCi} / \mathrm{L}$ \\
\hline 33 & Plutonium-239 & 6 & $2.41 \mathrm{E}+04$ & $2.54 \mathrm{E}+02$ & $1.35 \mathrm{E}-10$ & alpha & $15 \mathrm{pCi} / \mathrm{L}$ \\
\hline 34 & Plutonium-240 & 6 & $6.56 \mathrm{E}+03$ & $8.16 \mathrm{E}+01$ & $1.35 \mathrm{E}-10$ & alpha & $15 \mathrm{pCi} / \mathrm{L}$ \\
\hline 35 & Plutonium-241 & 6 & $1.44 \mathrm{E}+01$ & $1.18 \mathrm{E}+03$ & $1.76 \mathrm{E}-12$ & beta & $300 \mathrm{pCi} / \mathrm{L}$ \\
\hline 36 & Plutonium-242 & 6 & $3.75 \mathrm{E}+05$ & $4.43 \mathrm{E}-02$ & $1.28 \mathrm{E}-10$ & alpha & 15 pCi/L \\
\hline 37 & Americium-241 & 6 & $4.33 \mathrm{E}+02$ & $6.14 \mathrm{E}+01$ & $1.04 \mathrm{E}-10$ & alpha & $15 \mathrm{pCi} / \mathrm{L}$ \\
\hline 38 & Americium-243 & 6 & $7.37 \mathrm{E}+03$ & $2.36 \mathrm{E}-03$ & $1.03 \mathrm{E}-10$ & alpha & $15 \mathrm{pCi} / \mathrm{L}$ \\
\hline 39 & Curium-244 & 6 & $1.81 \mathrm{E}+01$ & $3.92 \mathrm{E}+01$ & $8.36 \mathrm{E}-11$ & alpha & $15 \mathrm{pCi} / \mathrm{L}$ \\
\hline
\end{tabular}




\subsection{Regulatory Boundary}

The hypothetical model was used to calculate the regulatory based (MCL) contaminant boundary through a 1000-yr period. In an effort to better understand the contribution of the three regulatory categories (alpha, beta, and uranium) to the composite boundary, the individual category maps were calculated along with the composite boundary in Figure 5.2. As shown in Figure 5.2, the alpha and uranium boundary is restricted to the source area, and the beta boundary encompasses a much larger area. The composite boundary is dominated solely by the beta-emitting radionuclides. Upon further examination of specific radionuclides, it is clear that carbon-14 and iodine-129 contributed to the large areal extent of the beta boundary. Carbon-14 has a large half life (5.73 x $10^{3}$ years), is not assumed to be entrained in the puddle glass, and is assumed to be a non-reacting isotope. Iodine-129 is also conservative, has a large half life (1.57 $\mathrm{x} 10^{7}$ years) and although only 50 percent of its mass is assumed to be trapped in the puddle glass, the MCL $(1 \mathrm{pCi} / \mathrm{L})$ is the smallest of all of the beta-emitting radionuclides.

Uranium Concentration $>30$ ug/L
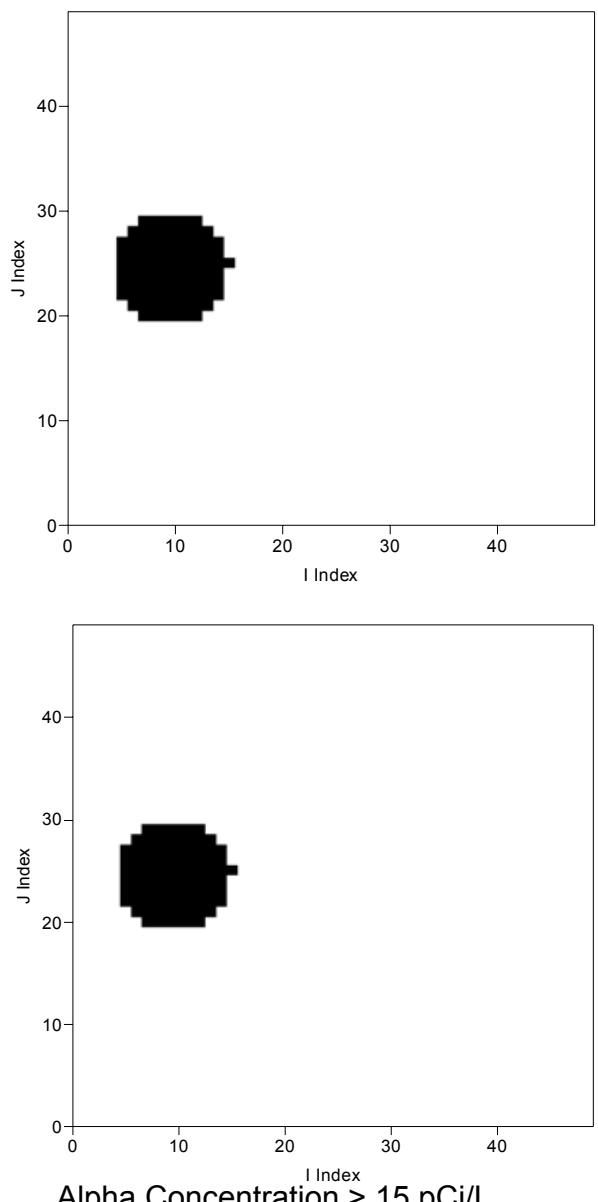

Alpha Concentration $>15 \mathrm{pCi} / \mathrm{L}$
Sum of Beta Ratio > 1.0
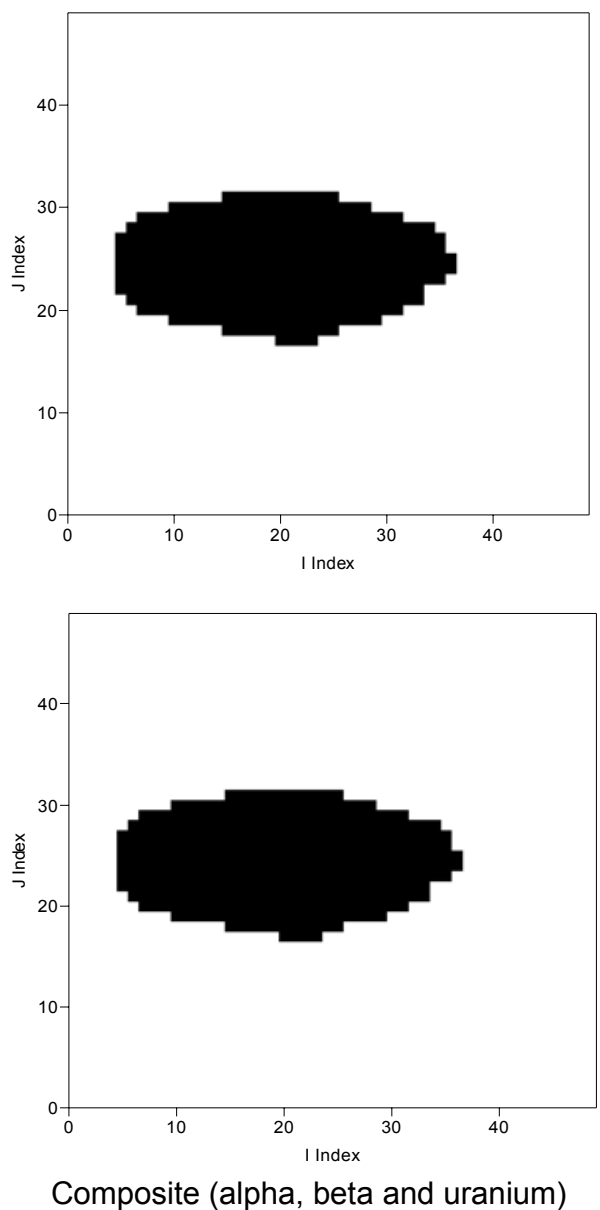

Figure 5.2. Regulatory contaminant boundary at the 95 percent significance level and 1,000 years for uranium, alpha, beta, and all (composite) categories as calculated from the hypothetical model. The boundaries are plotted for an $\mathrm{x}-\mathrm{y}$ section with $i$ and $j$ corresponding to the $\mathrm{x}$ and $\mathrm{y}$ directions, respectively. 


\subsection{Risk-based Boundary}

The risk-based boundary was calculated through a 1,000-year period and compared to the regulatory based boundary in Figure 5.3. The two boundaries are identical for the hypothetical model using the source term as derived from the average of area 19 and 20 nuclear tests. As noted above, combinations of radionuclides in groundwater might yield estimates of lifetime excess cancer that could exceed a risk-based standard of $10^{-6}$, even though a categorical MCL may not be exceeded. In the hypothetical example, the magnitude of the source term is relatively large, thereby yielding large dissolved concentrations. The solute transport model has a limited ability to resolve concentration values, which is dependent on the source term magnitude and the number of particles used to simulate radionuclide migration. Therefore, the hypothetical model was unable to resolve concentrations down to the levels that define the MCL $(\sim 1 \mathrm{pCi} / \mathrm{L})$. It
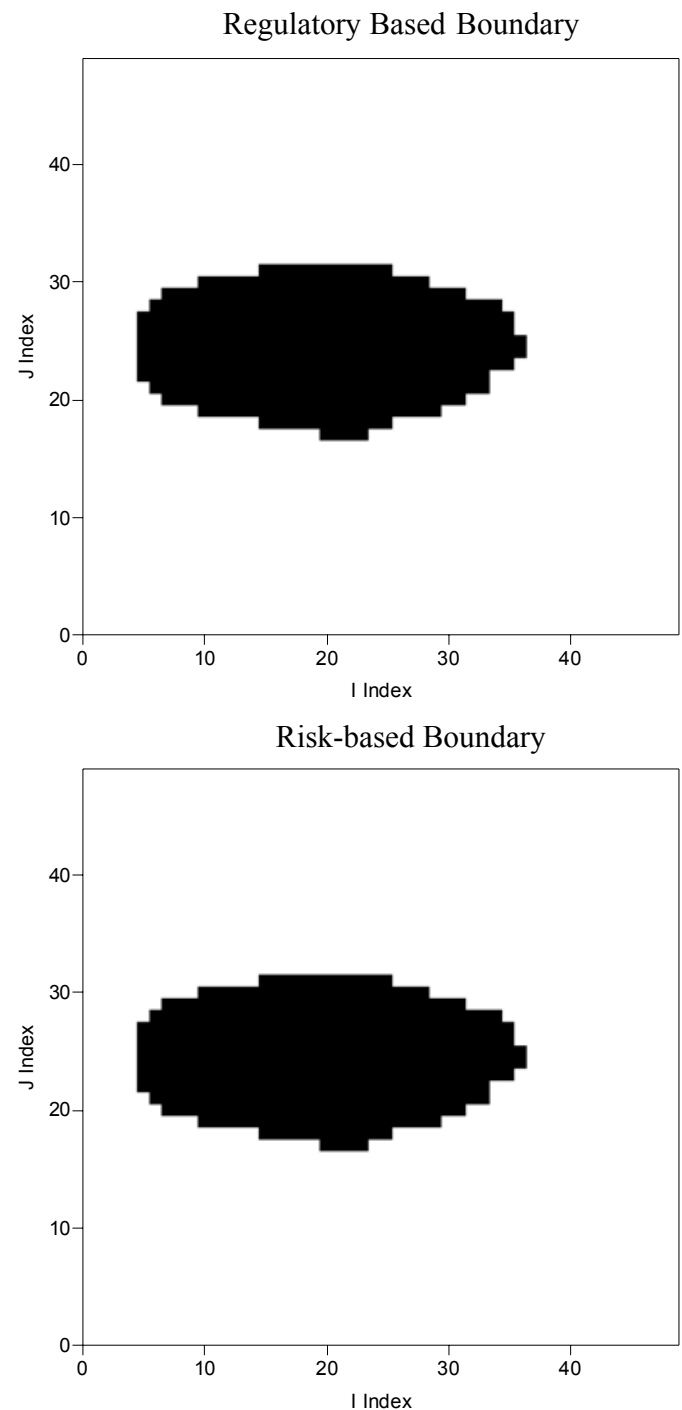

Figure 5.3. Regulatory (top) and risk-based (bottom) contaminant boundaries at the 95 percent significance level and 1,000 years as calculated from the hypothetical model. The boundaries are plotted for an $\mathrm{x}-\mathrm{y}$ section with $i$ and $j$ corresponding to the $\mathrm{x}$ and $\mathrm{y}$ directions, respectively. 
stands to reason that if additional particles were used in the transport calculations, then minor differences between the regulatory and risk-based boundaries could be observed.

\subsection{Comparison of Statistical Approaches}

Figure 5.4 shows a comparison of the two possible statistical interpretations of the contaminant boundary for three significance levels (5, 50 and 95 percent). Because of the complementary nature of the two boundary types, the boundary excluding the area of clean water (proposed here for the contaminant boundary calculation) at a 95 significance level is identical to the boundary encompassing the contaminated water at 5 percent. As a direct result, the boundary

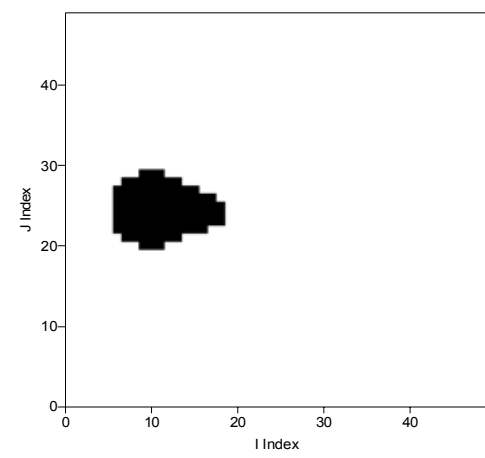

Confidence Level $=95 \%$
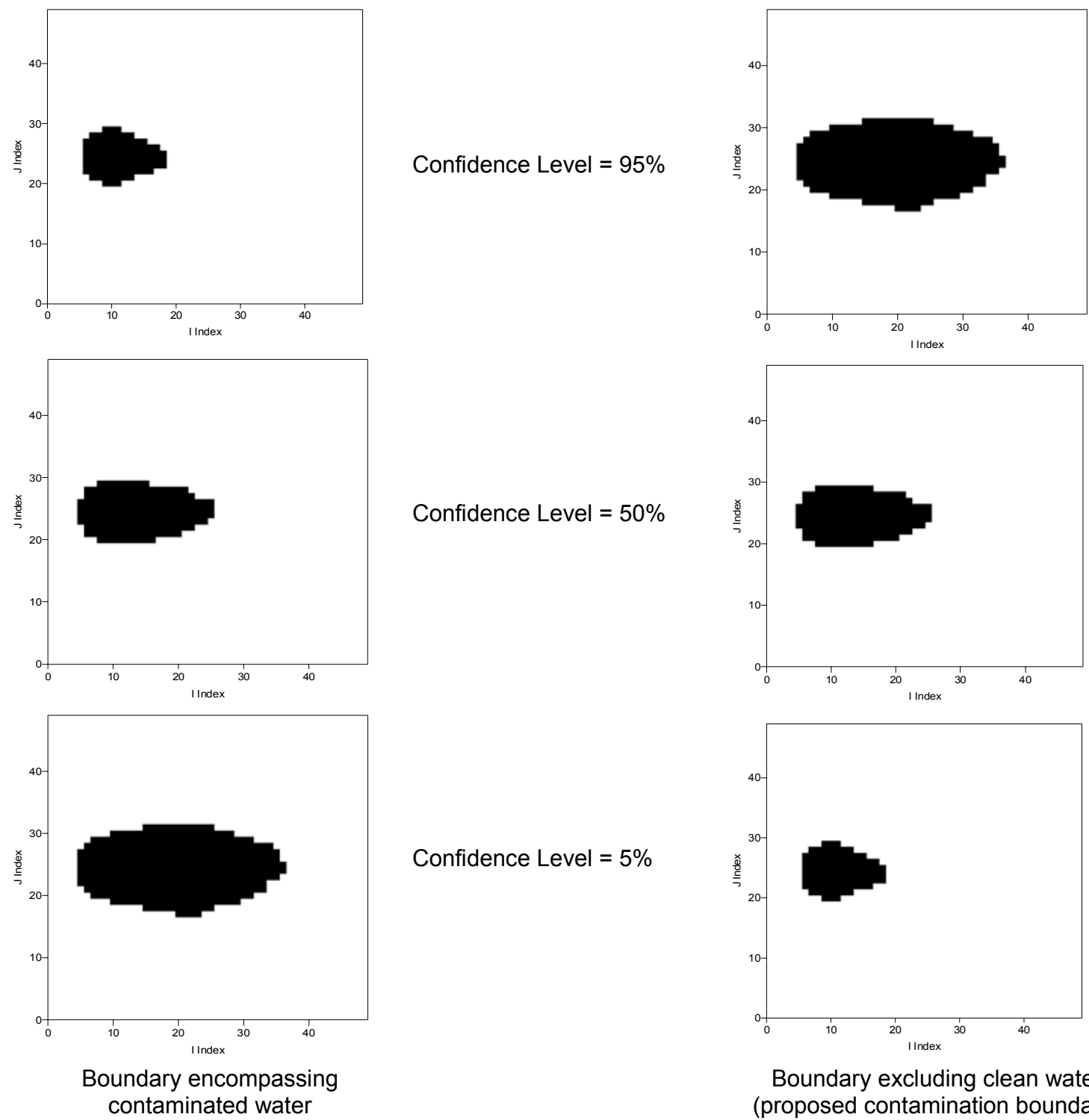

Boundary excluding clean water (proposed contamination boundary)

Figure 5.4. A comparison of the two statistical approaches at 5,50 and 95 percent confidence levels. The boundaries are plotted for an $\mathrm{x}-\mathrm{y}$ section with $i$ and $j$ corresponding to the $\mathrm{x}$ and $\mathrm{y}$ directions, respectively. The focus of the boundaries on the left side is identifying where the contaminated water exists, while the focus on the boundaries on the right side is focusing on where the water is uncontaminated. 
developed to exclude the area of clean water will always yield a larger impacted region if the same significance level is used to calculate both approaches. Likewise, the boundaries are identical at the 50 percent significance level.

\subsection{Temporal Boundary Maps}

The boundary maps are calculated as an accumulation of risk through the time period of interest. Figure 5.5 shows the contaminant boundary as calculated at 70, 280, 560, and 1,000 years. One could calculate an instantaneous boundary representing the risk at a specific time, but at least in the case of the hypothetical example, both the instantaneous and cumulative approaches yield the same result. The boundaries are equivalent because of the large number of radionuclides used to calculate the boundary. For example, if only a single radionuclide was used (e.g., tritium), then the instantaneous boundary area would increase and then decrease with time due to the relatively short half life. In this case, the two instantaneous and cumulative boundaries would be different, especially at greater times. When all of the radionuclides are used in the boundary calculation, there are numerous intersecting plumes due to sorption and glass dissolution processes. The plume intersections produce a temporal filtering effect that leads to similar instantaneous and cumulative boundaries.
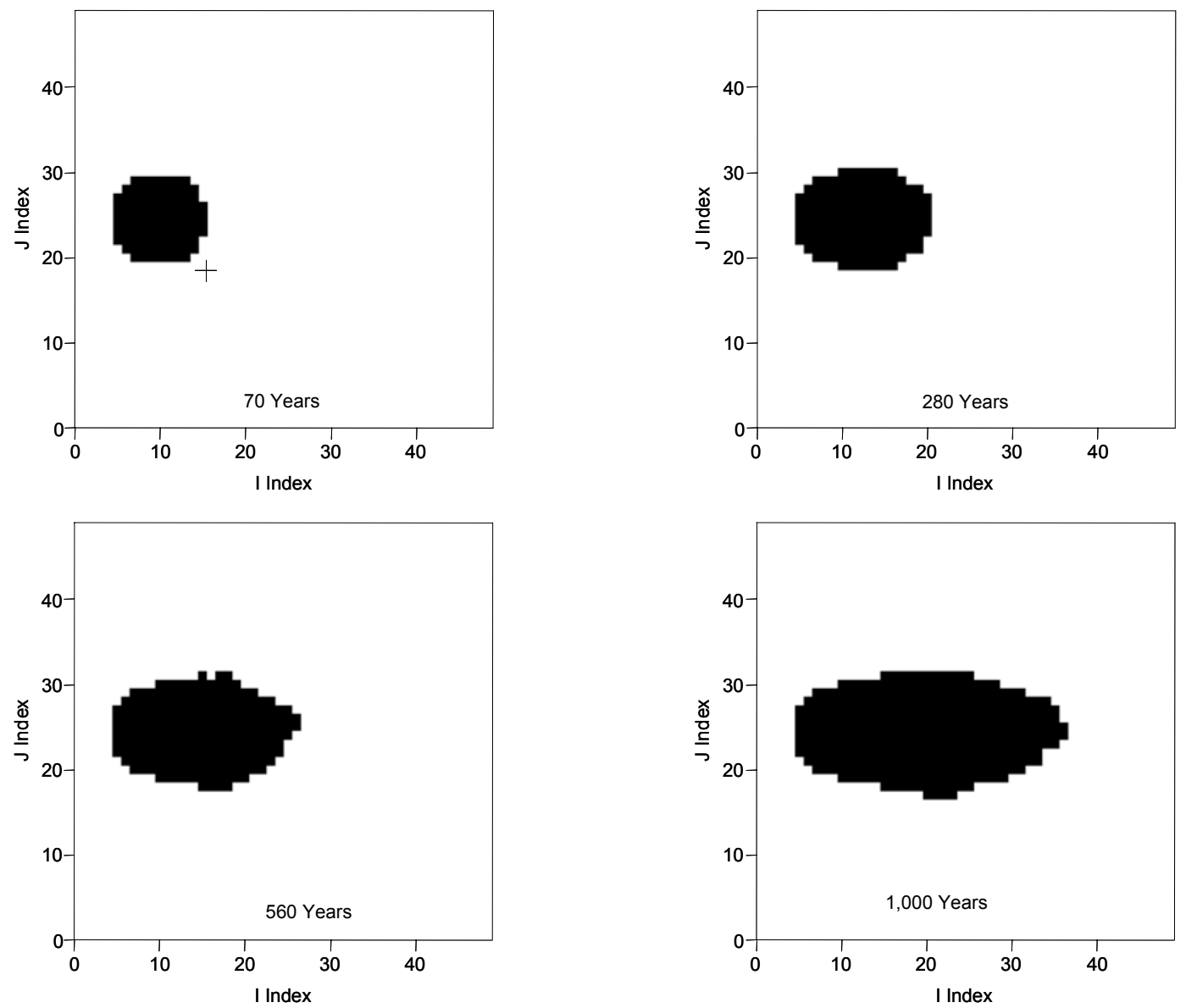

Figure 5.5. A time sequence of the proposed contaminant boundary at the 95 percent significance level as calculated from the hypothetical groundwater flow and transport model. The boundaries are plotted for an $\mathrm{x}-\mathrm{y}$ section with $i$ and $j$ corresponding to the $\mathrm{x}$ and $\mathrm{y}$ directions, respectively. 


\subsection{CONTAMINANT BOUNDARY FOR THE FAULTLESS UNDERGROUND NUCLEAR TEST, CAU 443}

The contaminant boundary for the Faultless underground nuclear test is determined using the revised groundwater flow and transport model presented in section 2 . Both a risk-based and regulatory based calculation is presented. The methodology used for the calculation focuses on identifying the region where there is a 95 percent certainty that water is "clean" based on either the risk or MCL standard. This region is external (outside) to the boundary. The region internal to this boundary is 5 percent certain to contain water exceeding the risk or MCL standard.

Contaminant boundaries using the risk-based calculation at a significance level of 95 percent are presented at 100 and 1,000 years after detonation in Figures 6.1 and 6.2, respectively. As described in Pohlmann et al. (1999), the calculated groundwater infill time is 30 years. Although other time periods could be presented, the contaminant boundary region does not change significantly during the 1,000-year simulation period. The contaminant boundary identifies the region where there is 95 percent certainty that contaminants do not pose a health risk external to the boundary delineation.

Contaminant boundaries using the regulatory based calculation at a significance level of 95 percent are presented at 100 and 1,000 years after detonation in Figures 6.3 and 6.4, respectively. Although the regulatory and risk-based calculations are based on slightly different risk

thresholds, the boundary maps are identical. The similarities are likely due to the slow migration of radionuclides, which causes sharp contaminant fronts with large activity concentrations. In this case, the activity concentrations within the contaminant plume are well above the MCL standard and would therefore cause large risk values. 

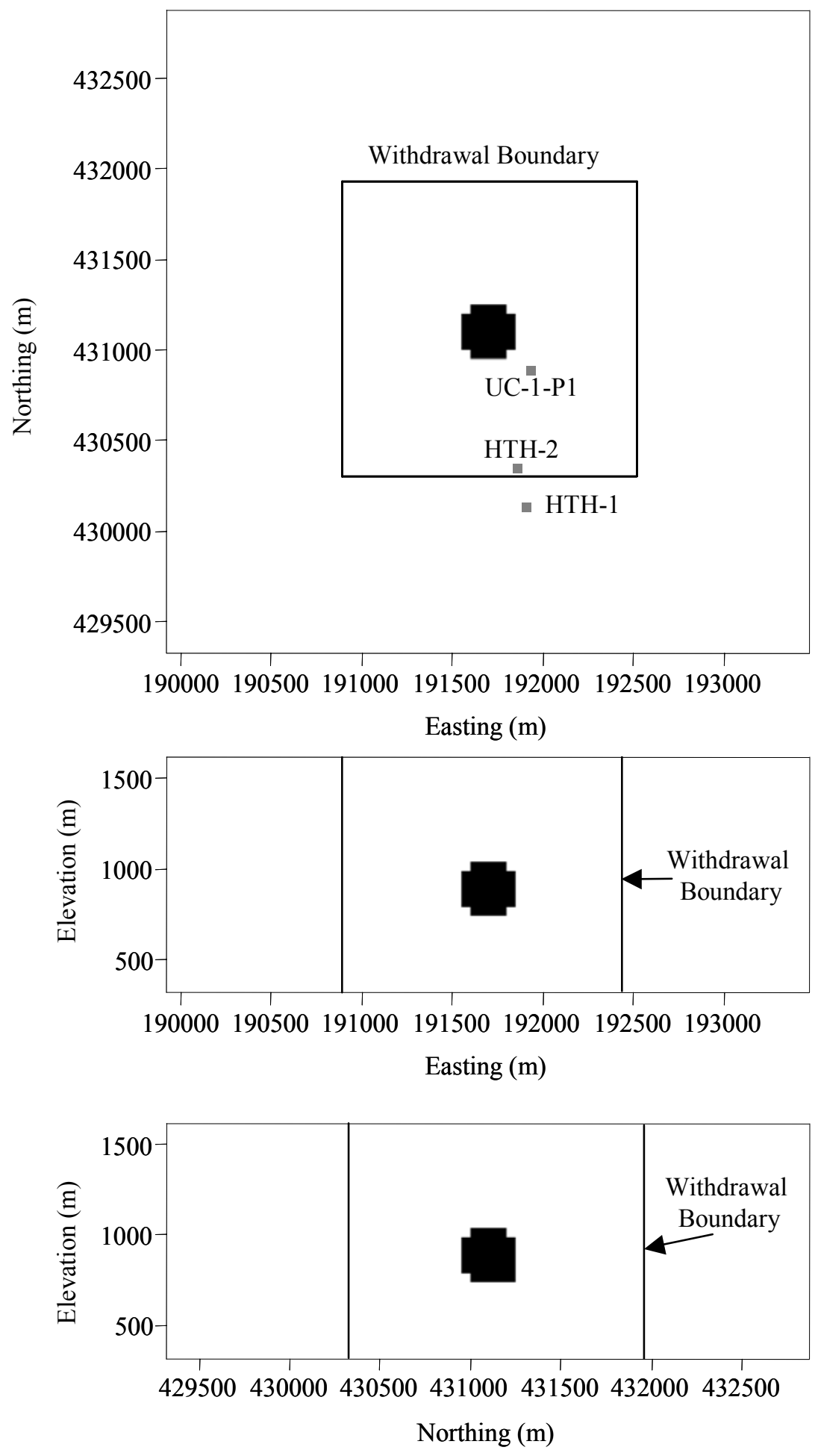

Figure 6.1. Contaminant boundary using the risk-based approach at a 95 percent significance level at 100 years after detonation. 

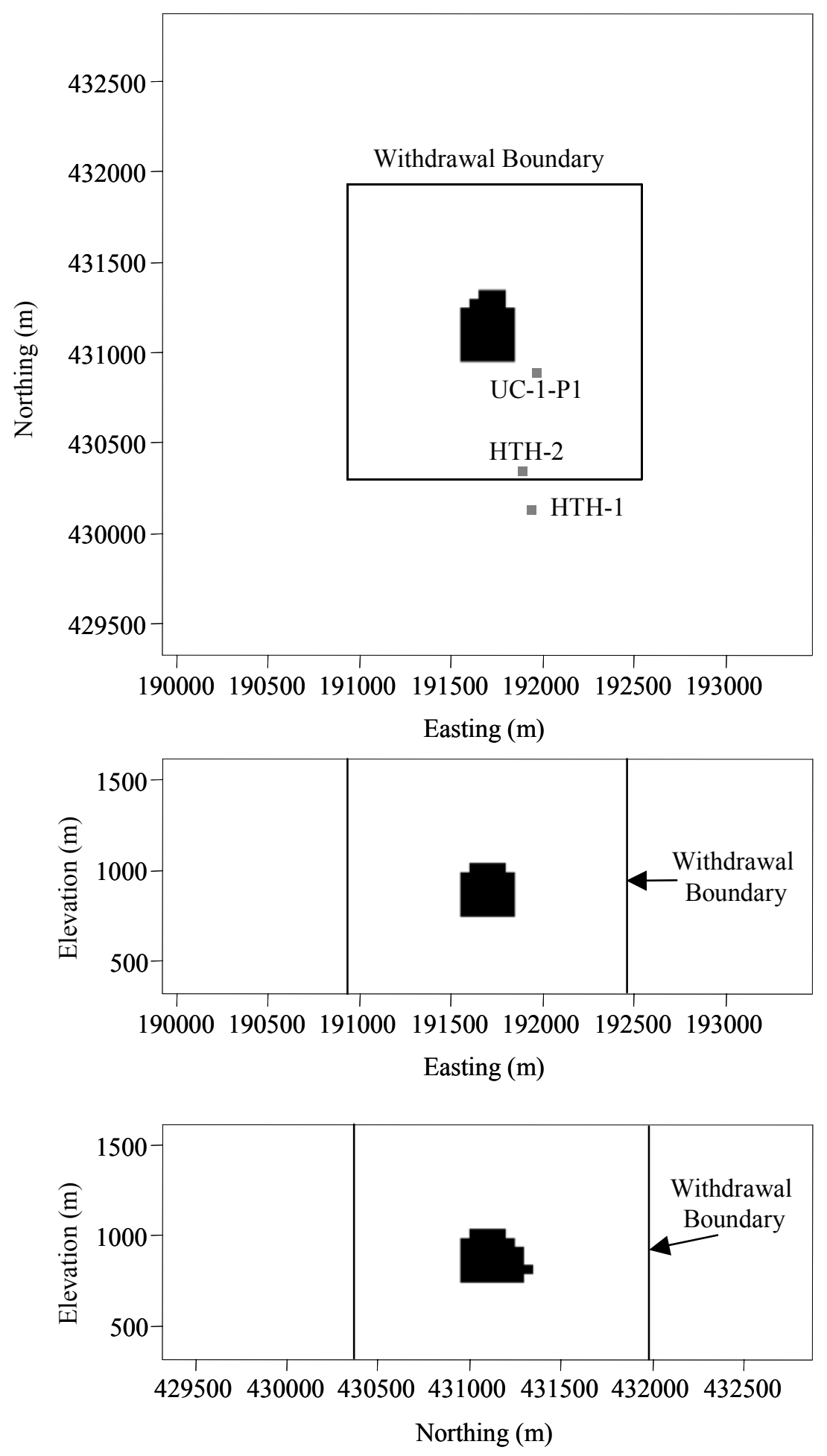

Figure 6.2. Contaminant boundary using the risk-based approach at a 95 percent significance level at 1,000 years after detonation. 


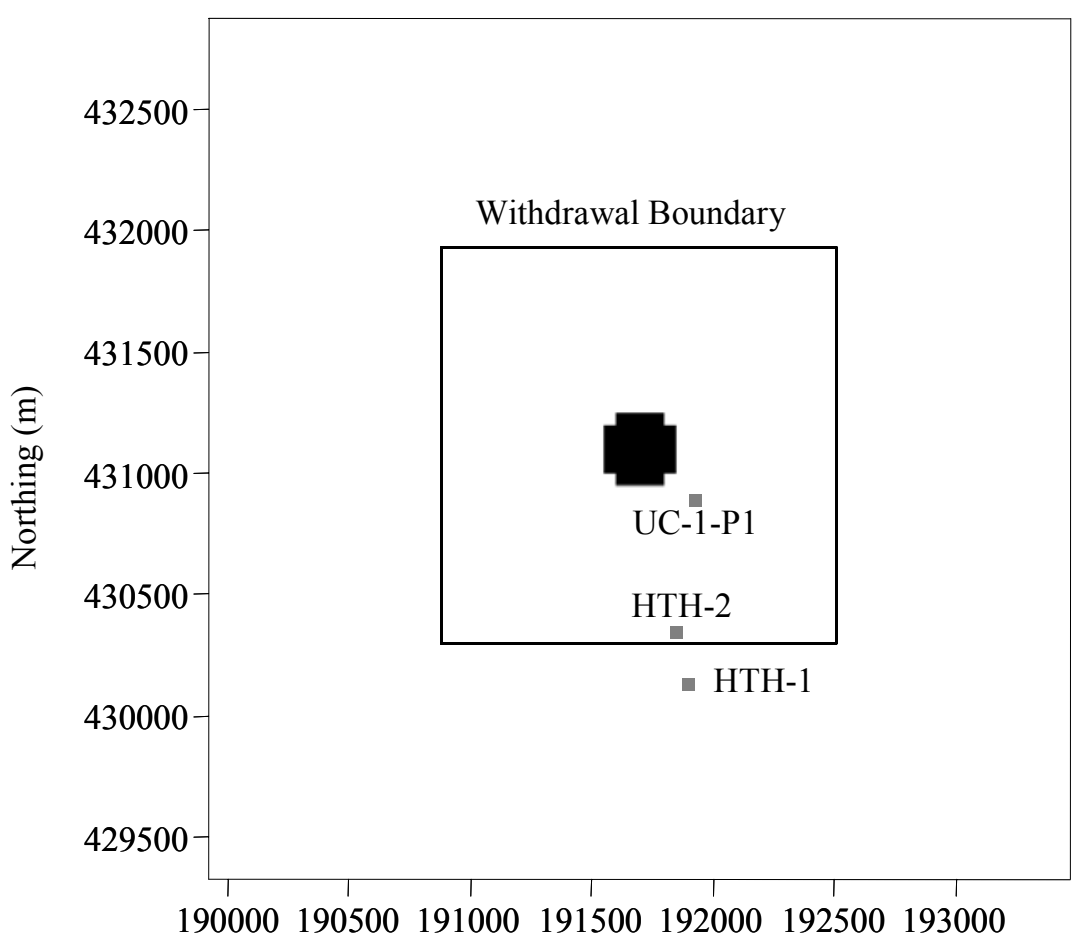

Easting (m)
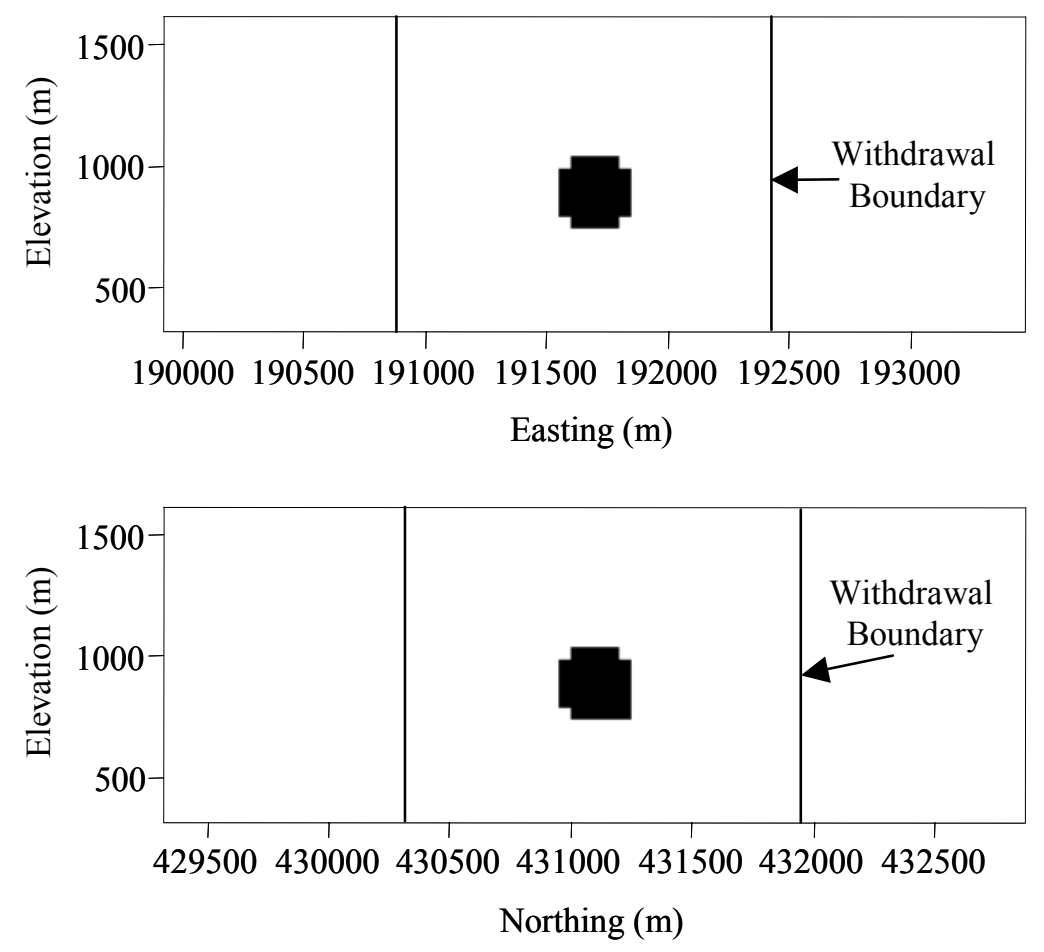

Figure 6.3. Contaminant boundary using the regulatory based approach at a 95 percent significance level at 100 years after detonation. 

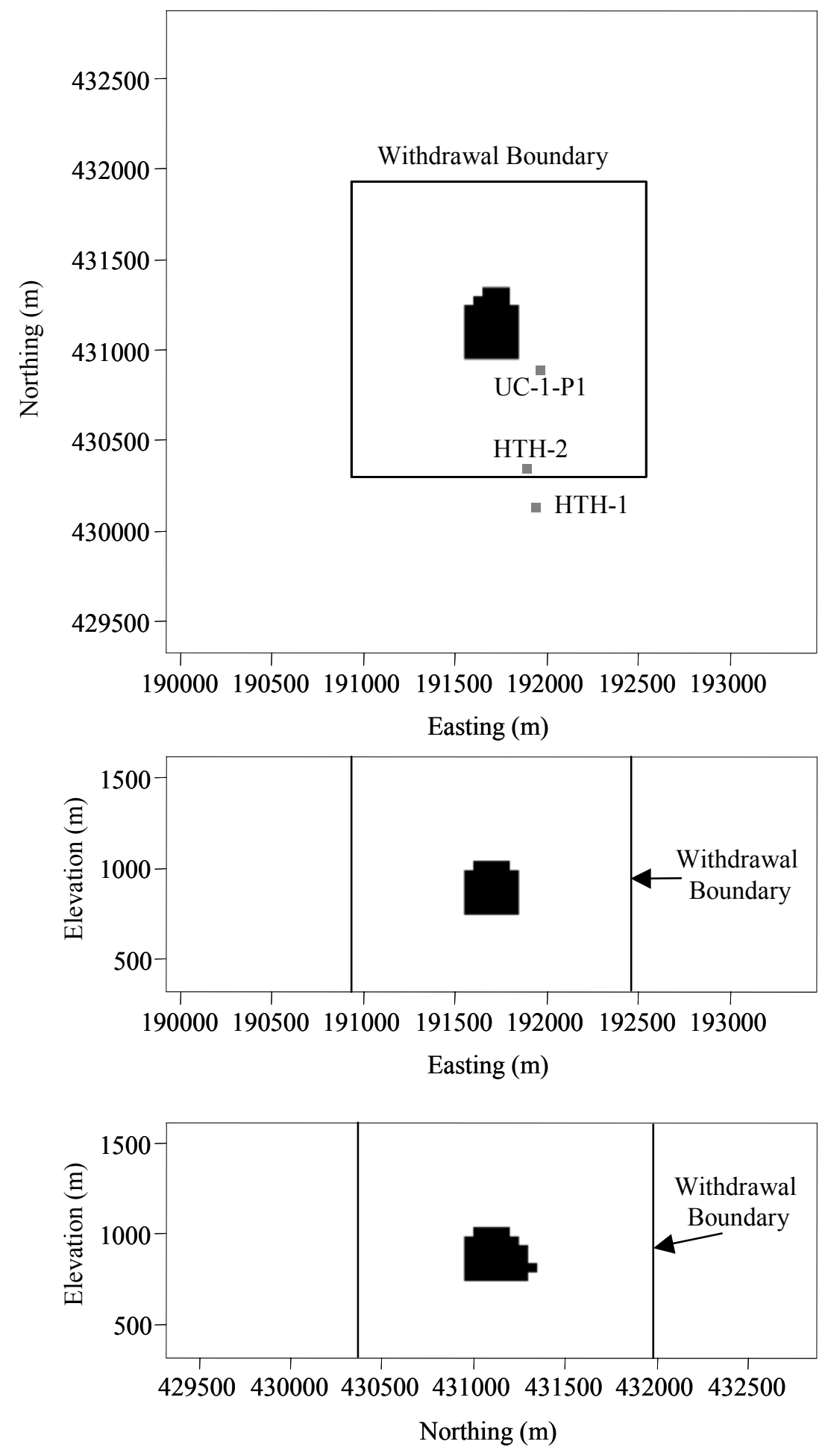

Figure 6.4. Contaminant boundary using the regulatory based approach at a 95 percent significance level at 1,000 years after detonation. 



\subsection{CONCLUSIONS}

This report documents the revisions to the CNTA groundwater flow and transport model, describes the methodology to calculate the contaminant boundary, and presents the boundary for the Faultless underground nuclear test.

The contaminant boundary for the Faultless underground nuclear test at the Central Nevada Test Area is calculated using a newly developed groundwater flow and radionuclide transport model that incorporates aspects of both the original three-dimensional model (Pohlmann et al., 1999) and the two-dimensional model developed for the Faultless data decision analysis (DDA) (Pohll and Mihevc, 2000). The original three-dimensional model was approved by the State of Nevada conditional on additional uncertainty analysis, which was performed in the DDA. To be true to the state's intent for a more rigorous incorporation of uncertainty, DOE/Nevada Operations Office decided to enhance the original three-dimensional model with the uncertainty features developed in the DDA before proceeding with determining contaminant boundaries for Faultless. This new model includes the uncertainty in the three-dimensional spatial distribution of lithology and hydraulic conductivity from the 1999 model as well as the uncertainty in the other flow and transport parameters from the 2000 DDA model. Additionally, the new model focuses on a much smaller region than was included in the earlier models; that is, the subsurface within the UC-1 land withdrawal area where the 1999 model predicted radionuclide transport will occur over the next 1,000 years.

These boundaries define over a 1,000-yr time period, with uncertainty quantified, the threedimensional extent of groundwater that would be considered safe for domestic and municipal use around the nuclear test under ambient (non-pumped) conditions. Two metrics for defining "safe" are considered: a $10^{-6}$ risk threshold, and a regulatory based threshold. In application to Faultless, there is no difference between the boundary calculated using risk as compared to the SDWA regulations. 



\subsection{REFERENCES}

Alabert, F., 1987. Stochastic Imaging of Spatial Distributions Using Hard and Soft Information. Master's Thesis, Stanford University, Stanford, CA.

American Society of Mechanical Engineers Center for Research and Technology Development and Institute for Regulatory Science (ASME/IRS), 2001. Technical Peer Review Report, Report of the Review Panel: Strategy for Remediation of Groundwater Contamination at the Nevada Test Site, The American Society of Mechanical Engineers, Technical Publishing Department, New York, NY, CRTD-Vol. 62.

Andricevic, R., J.I. Daniels, and R.L. Jacobson, 1994. "Radionuclide Migration Using a Travel Time Transport Approach and Its Application in Risk Analysis," J. Hydrol., 163, 125-145.

Beven, K.J., \& A.M. Binley, 1992. The future of distributed models: Model calibration and uncertainty prediction. Hydrological Processes, 6:279-298.

Bourcier, W., S. Roberts, D.K. Smith, S. Hulsey, L. Newton, A. Sawvel, C. Bruton, C. Papelis, W. Um, C. Russell and J. Chapman, 2000. Determination of Reactive Surface Area of Melt Glass. Lawrence Livermore National Laboratory report UCRL-ID-145181, 86 p.

Cvetkovic, V. and G. Dagan, 1994. Transport of kinetically sorbing solutes by steady random velocity in heterogeneous porous formations. J. Fluid Mech., 265, 189-215.

Daniels, J.I., K.T. Bogen, and L.C. Hall, 2000. Analysis of Uncertainty and Variability in Exposure to Characterize Risk: Case Study Involving Trichlorethylene Groundwater Contamination at Beale Air Force Base in California. Water, Air, Soil Pollut., 123:273-298.

Daniels, J.I., R. Andricevic, L.R. Anspaugh, and R.L. Jacobson, 1993. “4. Risk-Based Screening Analysis of Ground Water Contaminated by Radionuclides Introduced at the Nevada Test Site," in Pilot Study Risk Assessment for Selected Problems at the Nevada Test Site (NTS), J.I. Daniels, Ed., Lawrence Livermore National Laboratory, Livermore, CA, UCRL-LR-113891.

Deutsch, C.V. and A.G. Journel, 1998. GSLIB Geostatistical Software Library and User's Guide, 1998. Oxford University Press, 2nd edition.

Federal Facility Agreement and Consent Order for Nevada (FFACO), 2000. Appendix VI. Corrective Action Strategy Section 3. Underground Test Area, in Nevada Federal Facility Agreement (FFACO), Agreement Between the U.S. Department of Energy (National Nuclear Security Administration), the State of Nevada (Nevada Division of Environmental Protection), and the U.S. Department of Defense (Defense Threat Reduction Agency), available from U.S. Department of Energy, National Nuclear Security Administration, Nevada Operations Office, Las Vegas, NV (December 7, 2000; Revision: 1); reissued on compact disc January 2002, to include revisions to any part of the FFACO that occurred since the July 2001 version was released.

Freer, J. and K. Beven, 1996. Bayesian estimation of uncertainty in runoff prediction and the value of data: An application of the GLUE approach. Water Resour. Res., 32(7):2161-2173.

Glasstone, S., \& P.J. Dolan, 1977. The Effects of Nuclear Weapons (3rd ed.). U.S. Department of Defense and U.S. Department of Energy. 
Hassan, A.E. and M.M. Mohammed, 2003. On using the random walk particle tracking method to simulate transport in single-continua porous media: a comparative study. Journal of Hydrology.

Hill, M.C., 1990. Preconditioned Conjugate-Gradient 2 (PCG2), A computer program for solving ground-water flow equations. U.S. Geological Survey, Denver, Colorado.

Huber, D., 2001. Derived Concentrations (pCi/L) of Beta and Photon Emitters in Drinking Water, Yielding a Dose of $4 \mathrm{mrem} / \mathrm{y}$ to theTotal Body or to Any Critical Organ as Defined in NBS Handbook 69, Standards and Risk Management Division, Office of Ground Water and Drinking Water, Washington, DC (Personnel E-mail Correspondence; Voice Telephone: 202-564-4878/202-260-9566).

Kinzelbach, W., 1988. The random walk method in pollutant transport simulation, In Groundwater Flow and Quality Modeling, eds. E. Custodio, A. Gurgui, J.P. Lobo Ferreira, D. Reidel, Norwell, Mass, 227-246.

Knuth, D.E., 1981. The Art of Computer Programming Vol. 2: Seminumerical Methods (second edition), Addison-Wesley, Reading, Mass.

LaBolle, E., G. Fogg and A.F.B. Tompson, 1996. Random-walk simulation of solute transport in heterogeneous porous media: Local mass-conservation problem and implementation methods. Water Resour. Res., 32:583-593.

LaBolle, E., J. Quastel, G. Fogg and J. Gravner, 2000. Diffusion processes in a composite porous media and their integration by random walks: Generalized stochastic differential equations with discontinuous coefficients. Water Resour. Res., 36:651-662.

Liu, H.H., G.S. Bodvarsson and L. Pan, 2000. Determination of particle transfer in random walk particle methods for fractured porous media. Water Resour. Res., 36(3):707-713.

Marsaglia, G.A., 1985. A current view of random number generators, in Computational Science and Statistics: The Interface, ed. L. Balliard, Elsevier, Amsterdam.

Maxwell, R.M., S.D. Pelmulder, A.F.B. Tompson, and W.E. Kastenberg, 1998. On the Development of a New Methodology for Groundwater-Driven Health Risk Assessment. Water Resour. Res., 34: 833-847.

McDonald, M.G. and A.W. Harbough, 1988. A Modular Three-Dimensional Finite-Difference Ground-Water Flow Model. Techniques of Water Resources Investigations, Book 6, Chap. A1, U.S. Geological Survey.

Moeller, D.W., 1992. "Chapter 10. Standards," in Environmental Health (Harvard University Press, Cambridge, MA), pp. 225-228.

Morse, B.S., G. Pohll, J. Huntington, and R. R. Castillo (In Press). Stochastic capture zone analysis of an arsenic-contaminated well using the GLUE methodology. Water Resource Research.

Pohll, G., and T. Mihevc, 2000. Data Decision Analysis: Central Nevada Test Area. Desert Research Institute, Division of Hydrologic Sciences Report 45179.

Pohll, G., J. Tracy, and F. Forsgren, 1998. Data Decision Analysis: Project Shoal. Desert Research Institute, Division of Hydrologic Sciences Report 45166. 
Pohlmann, K., J. Chapman, A. Hassan and C. Papelis, 1999. Evaluation of Groundwater Flow and Transport at the Faultless Underground Nuclear Test, Central Nevada Test Area. Publication No. 45165, Desert Research Institute, Division of Hydrologic Sciences.

Smith, David K., 2001. Unclassified Radiologic Source Term for Nevada Test Site Areas 19 and 20. Lawrence Livermore National Laboratory report UCRL-ID-141706, 4p.

Tompson, A.F.B. and L.W. Gelhar, 1990. Numerical simulation of solute transport in threedimensional randomly heterogeneous porous media. Water Resour. Res., 26(10):2541-2562.

United States Department of Energy, Nevada Operations Office, 2000. United States Nuclear Tests, July 1945 through September 1992, Las Vegas, NV, DOE/NV-209-REV 15, December 2000, United States Department of Energy, Nevada Operations Office.

United States Environmental Protection Agency (EPA), 1976. National Interim Primary Drinking Water Regulations, U.S. Environmental Protection Agency, Office of Water supply, Washington, DC, EPA-570-9-76-003; Reproduced by U.S. Department of Commerce National Technical Information Service, Springfield, VA; NTIS Accession No. PB267630 (1976); see Appendix B-Radionuclides (pp. 129-142) and Appendix IV (in Appendix B): Dosimetric Calculations for Man-Made Radioactivity, (pp. 152-159).

United States Environmental Protection Agency (EPA), 1988. Federal Guidance Report No. 11: Limiting Values of Radionuclide Intake and Air Concentration and Dose Conversion Factors for Inhalation, Submersion, and Ingestion, Office of Radiation Programs, United States Environmental Protection Agency, Washington, DC, EPA-520/1-88-020 (September 1988).

United States Environmental Protection Agency (EPA), 1999. Federal Guidance Report No. 13: Cancer Risk Coefficients for Environmental Exposure to Radionuclides, Office of Radiation and Indoor Air, United States Environmental Protection Agency, Washington, DC, EPA 402R-99-001.

United States Environmental Protection Agency (EPA), 2000a. "Part II. Environmental Protection Agency, 40 CFR Parts 9, 141, and 142: National Primary Drinking Water Regulations; Radionuclides; Final Rule," Fed. Regist. 65(236), 76708-76753 (December 7, 2000).

United States Environmental Protection Agency (EPA), 2000b. "Part IV. Environmental Protection Agency, 40 CFR Parts 9, 141, and 142: National Primary Drinking Water Regulations; Radionuclides; Notice of Data Availability; Proposed Rule," Fed. Regist. 65(78), 21576-21628 (April 21, 2000), see Table II-3, p. 21605-21614.

United States Environmental Protection Agency (EPA), 2002. "Section II. SDWIS Reporting, Violation, Determination, and SNC Definitions," in Implementation Guidance for Radionuclides, Washington, DC, EPA816-F-00-002. 


\section{APPENDIX: ASSESSMENT OF THE DEPENDENCE OF SOLUTE TRANSPORT MIGRATION ON DOMESTIC WELL PUMPING}

\section{INTRODUCTION}

A hypothetical groundwater flow and transport model was constructed to illustrate the impact of domestic well pumping on solute transport migration. A steady-state, two-dimensional flow model was used with constant head boundary conditions on the left- and right-most model boundaries to induce a hydraulic head gradient from left to right (Figure A-1). The other two edges of the domain were set as no-flow boundaries. A Gaussian hydraulic conductivity field was constructed with the mean set such that conservative solutes would move across the domain in a 1,000-year period and have a log-variance of 1.0. Only one realization was performed, as the purpose was to test the impact of well pumping and not to address uncertainty issues. Four cases were simulated to represent conditions of large and small effective porosity and hydraulic conductivity and pumping versus no pumping conditions. The effective porosity and hydraulic conductivity was three orders of magnitude larger for simulations 1 and 2 as compared to simulations 3 and 4 . Arbitrary length units were used for all simulations. The pumping rate for simulations 2 and 4 that included a well was set to 2 L/day, which would be much smaller than expected from a typical domestic well, but it illustrates the potential impacts on solute migration at the low end of the spectrum.

The source was located approximately near the left edge of the model domain with the primary flow direction being from left to right (Figure A-1). The source was represented as an instantaneous release of a conservative solute with a unit concentration. Time histories of solute breakthrough to the well (either pumping or not) and the spatial distribution of solute concentration at various times within the 1,000-year simulation are presented to determine the importance of including local pumping within the flow simulation.

\section{RESULTS}

The spatial distribution of solute concentration is shown in Figure A2 at 250, 500, and 750 years for simulations 1 and 2. As can be seen in Figure A2, the impact of the well is minimal when the effective porosity and hydraulic conductivity are large. Figure A3 shows the solute concentrations at 25, 90 and 260 years for simulations 3 and 4 . Clearly, under conditions of small hydraulic conductivity and effective porosity, even small pumping rates have a large impact on solute transport migration. When the porosity is small, the area of influence from a pumping well becomes much larger. In simulation 4 , the well is able to capture the entire solute plume.

The impact of pumping on solute breakthrough is shown in Figure A4, which shows the breakthrough curves at the well location for all four simulations. In Figure A4(a), when the effective porosity is large, there are only minor differences in the breakthrough curve behavior. When the effective porosity is increased, the breakthrough is much more rapid and concentrations smaller when a pumping well is included (Figure A4(b)). The rapid breakthrough is attributed to increased hydraulic gradients induced by the well, which cause increased velocities. The smaller concentrations are attributed to the large capture zone, which causes dilution at the wellbore. 


\section{CONCLUSIONS}

The results of the hypothetical simulations show the potential for wells to cause significant changes to the solute transport migration behavior. The differences between including a well and not including one become more pronounced as the hydraulic conductivity and effective porosity decrease.

The results suggest that contaminant boundary maps that are produced with the assumption that domestic wells have only a minor influence on radionuclide behavior may need to be modified under certain situations.

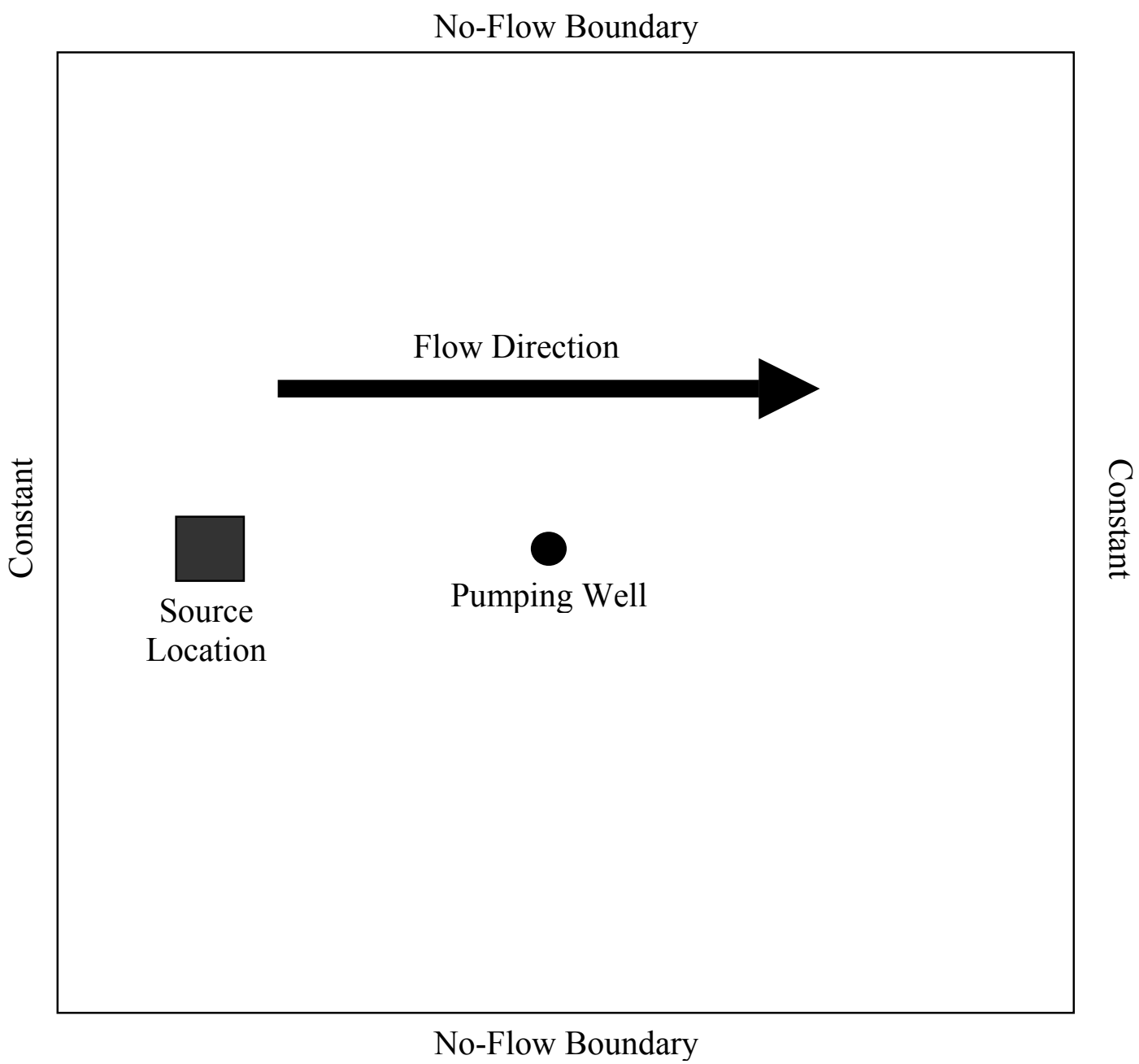

Figure A1. Hypothetical groundwater flow and transport components for the two-dimensional flow model. 

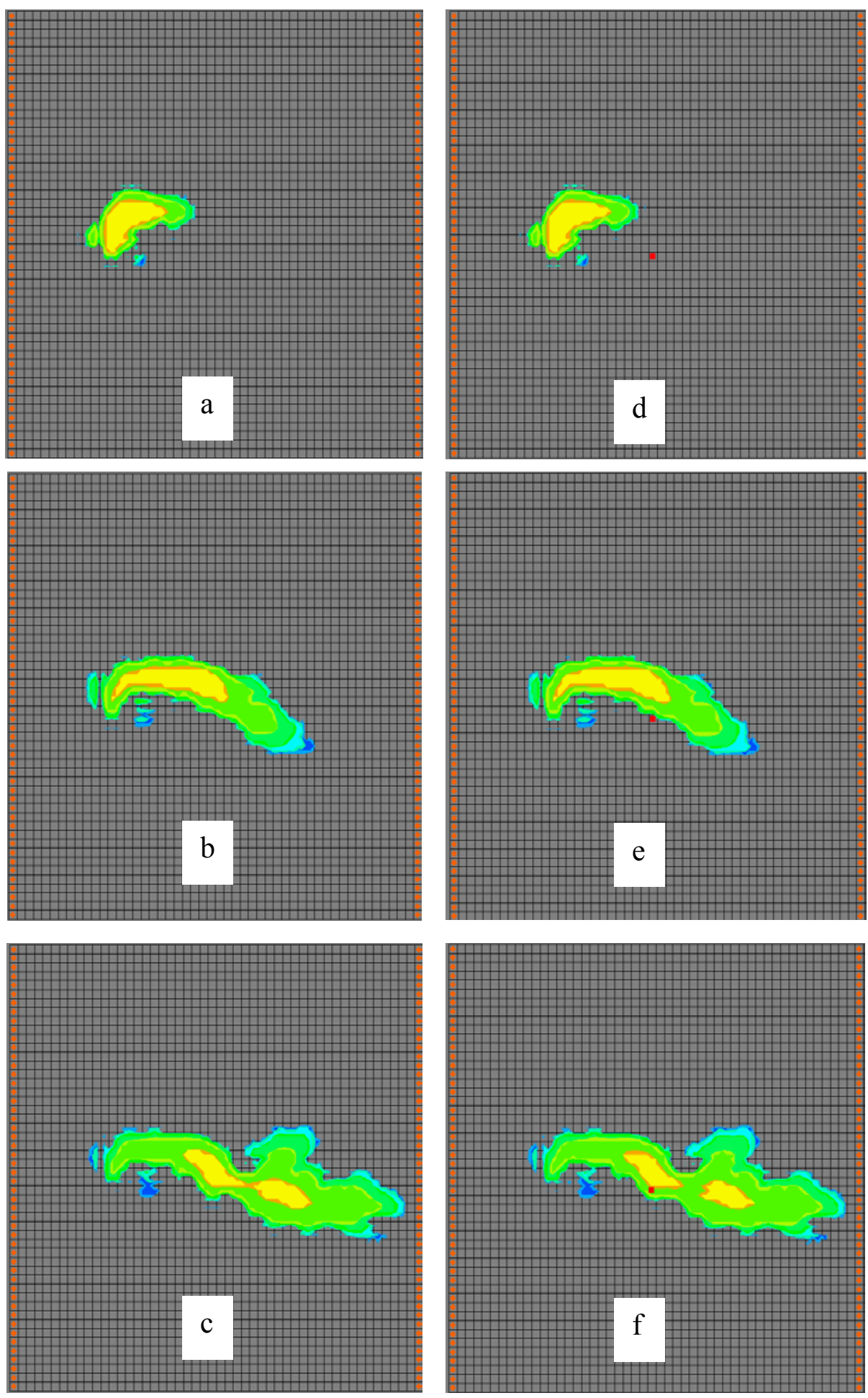

Figure A2. Spatial distribution of solute concentration for simulations 1 and 2 in the appendix. Images a, $\mathrm{b}$, and $\mathrm{c}$ represent the concentrations for the no-well simulation at 250, 500, and 750 years, respectively. Images $\mathrm{d}$, e, and f represent the concentrations for the simulation that included at pumping well at 250,500 , and 750 years, respectively. 

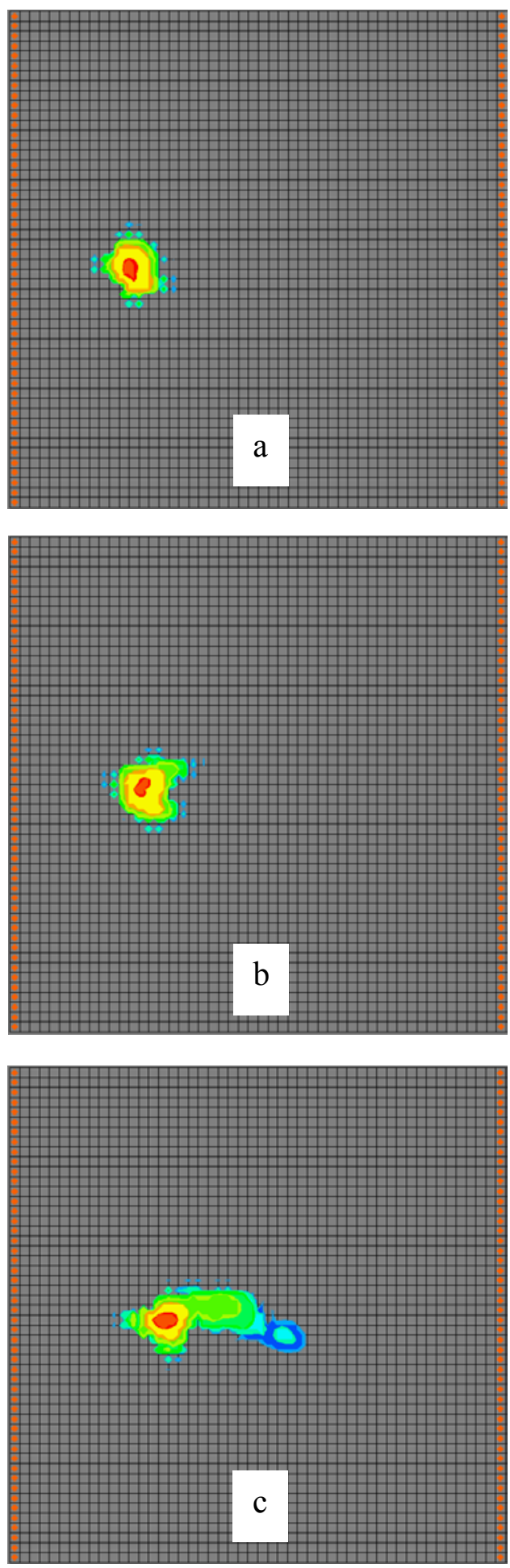
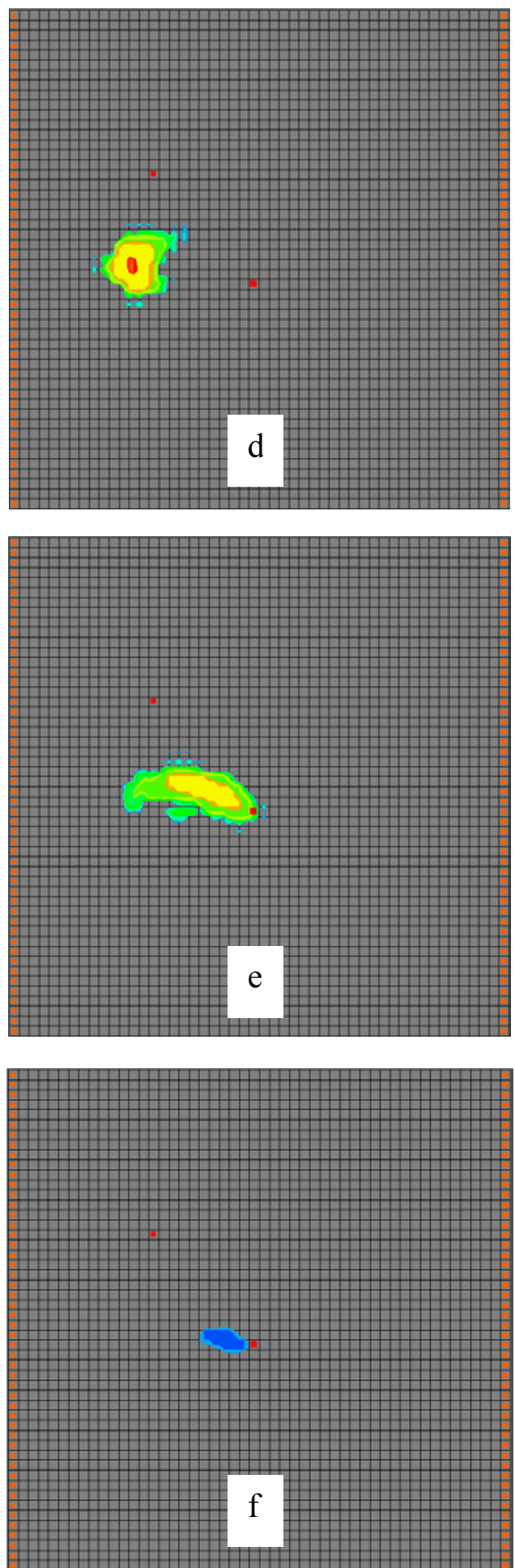

Figure A3. Spatial distribution of solute concentration for simulations 3 and 4 in the appendix. Images a, $\mathrm{b}$, and $\mathrm{c}$ represent the concentrations for the no-well simulation at 25, 90, and 260 years, respectively. Images $d$, e, and $f$ represent the concentrations for the simulation that included at pumping well at 25, 90, and 260 years, respectively. 

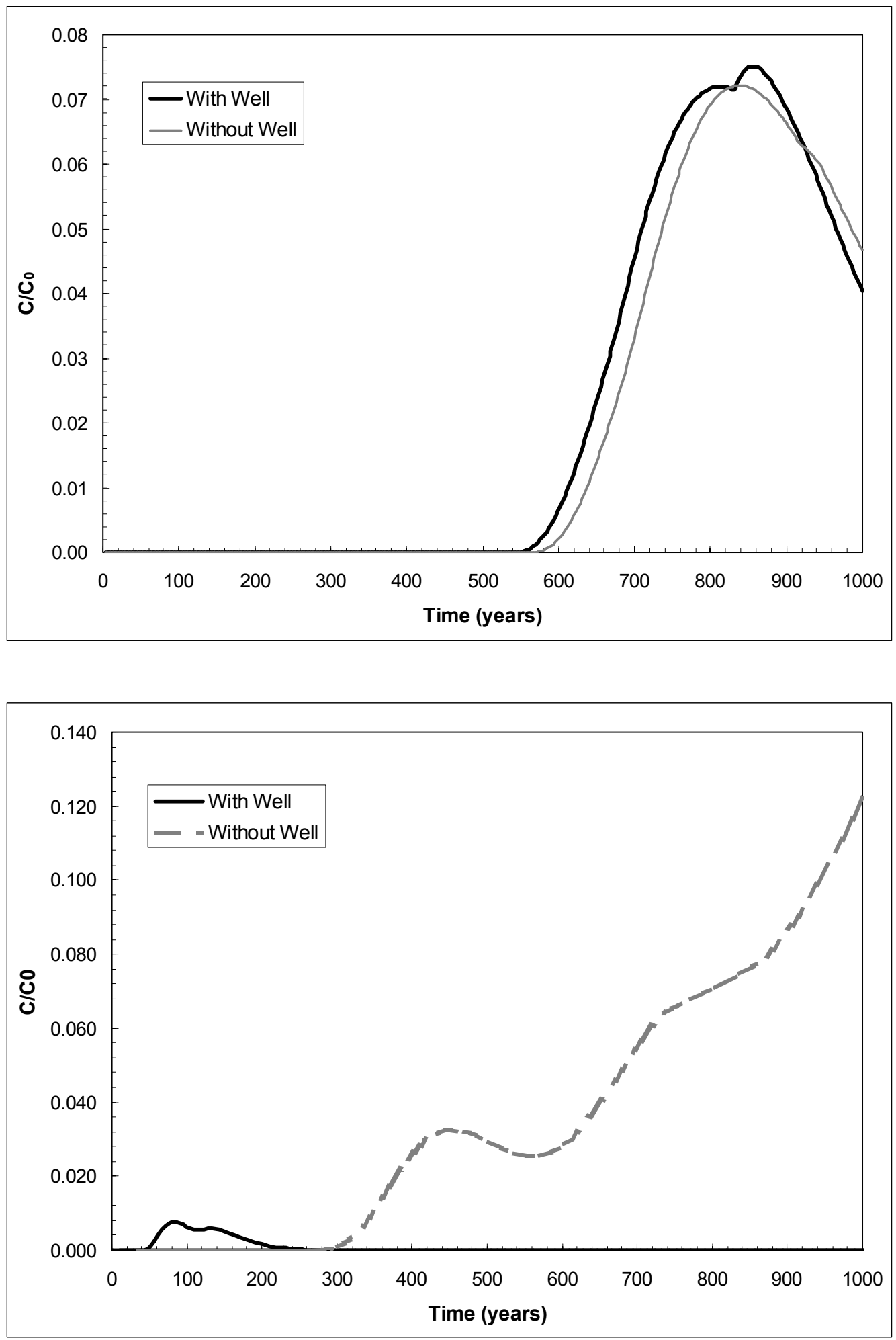

Figure A4. Solute breakthrough curves for simulations 1 and 2 (top) and 3 and 4 (bottom). 


\section{DISTRIBUTION}

Brian Cherry

Shaw Environmental, Inc.

P.O. Box 93838, M/S 439

Las Vegas, NV 89193-3838

Darby Dieterich

Office of Business Affairs

Nevada Site Office

National Nuclear Security Administration

U.S. Department of Energy

P.O. Box 98518

Las Vegas, NV 89193-8518

Bruce Hurley

Hydrology Program Manager

Environment, Safety \& Health Division

Nevada Site Office

National Nuclear Security Administration

U.S. Department of Energy

P.O. Box 98518

Las Vegas, NV 89193-8518

David Stahl

Shaw Environmental, Inc.

P.O. Box 93838, M/S 439

Las Vegas, NV 89193-3838

Kenneth A. Hoar, Director

Environment, Safety \& Health Division

Nevada Site Office

National Nuclear Security Administration

U.S. Department of Energy

P.O. Box 98518

Las Vegas, NV 89193-8518

Marjory Jones

Division of Hydrologic Sciences

Desert Research Institute

2215 Raggio Parkway

Reno, NV 89512-1095

Randy Laczniak

U.S. Geological Survey

Water Resources Division

6770 S. Paradise Rd.

Las Vegas, NV 89119
Monica Sanchez

Environmental Restoration Division

Nevada Site Office

National Nuclear Security Administration

U.S. Department of Energy

P.O. Box 98518

Las Vegas, NV 89193-8518

Peter Sanders

Environmental Restoration Division

Nevada Site Office

National Nuclear Security Administration

U.S. Department of Energy

P.O. Box 98518

Las Vegas, NV 89193-8518

David Shafer

Division of Hydrologic Sciences

Desert Research Institute

755 E. Flamingo Road

Las Vegas, NV 89119-7363

Runore C. Wycoff, Director

Environmental Restoration Division

Nevada Site Office

National Nuclear Security Administration

U.S. Department of Energy

P.O. Box 98518

Las Vegas, NV 89193-8518

Nevada State Library and Archives

State Publications

100 North Stewart Street

Carson City, NV 89710-4285

Archives

Getchell Library

University of Nevada, Reno

DeLaMare Library/262

University of Nevada, Reno

Document Section, Library

University of Nevada, Las Vegas

4505 Maryland Parkway

Las Vegas, NV 89154 
Library

Shaw Environmental, Inc.

Bldg. B-1

P.O. Box 93838, M/S 439

Las Vegas, NV 89193-3838

ATTN: Toni Miller, M/S 439

Library

Southern Nevada Science Center

Desert Research Institute

755 E. Flamingo Road

Las Vegas, NV 89119-7363

Technical Library

Nevada Site Office

National Nuclear Security Administration

U.S. Department of Energy

P.O. Box 98518

Las Vegas, NV 89193-8518

Public Reading Facility

Nevada Site Office

National Nuclear Security Administration

U.S. Department of Energy

P.O. Box 98521

Las Vegas, NV 89193-8521

Office of Scientific and Technical Information

U.S. Department of Energy

P.O. Box 62

Oak Ridge, TN 37831-9939

(electronic copy 